Linköping Studies in Science and Technology.

Dissertation No. 1847

\title{
The Physical Axon
}

Modeling, Simulation and Electrode Evaluation

\author{
Malcolm Latorre
}

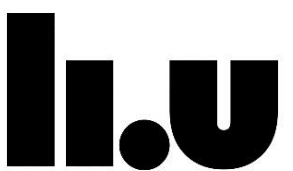

LINKÖPING UNIVERSITY

Department of Biomedical Engineering

Institute of Technology

Linköping's University,

SE-581 85 Linköping, Sweden

Linköping 2017 
Copyright $@$ Malcolm Latorre, 2017

All images under copyright and permission required from author for any use. Figures 7,10,11,12 are reproduced with permission from Malmivuo and Plonsey [16] E-Book. Figure 3 reproduced with permission from BMJ, Figure 5 is reproduced with permission from Brain Science

$\begin{array}{ll}\text { Main Supervisor } & \text { Karin Wårdell } \\ \text { Co-supervisor } & \text { Göran Salerud }\end{array}$

Printed in Sweden by LiU-Tryck Linköping, 2017

ISSN 0345-7524

ISBN 978-91-7685-529-4 
The Physical Axon

Modeling, Simulation and Electrode Evaluation

By

Malcolm A. Latorre

May 2017

ISBN: 978-91-7685-529-4

Linköping Studies in Science and Technology.

Dissertation No. 1847

ISSN 0345-7524

Keywords: action potential, electronic nerve model,

electrode characterization, DBS, electrode evaluation

Department of Biomedical Engineering

Linköping's University

SE-581 85 Linköping, Sweden 


\section{Dedication}

I dedicate this work

to my wife who has been in my thoughts through the tough times,

to my children whom I love deeply,

and

to my parents for their love and

encouragement throughout my life. 


\begin{abstract}
Electrodes are used in medicine for detection of biological signals and for stimulating tissue, e.g. in deep brain stimulation (DBS). For both applications, an understanding of the functioning of the electrode, and its interface and interaction with the target tissue involved is necessary. To date, there is no standardized method for medical electrode evaluation that allows transferability of acquired data. In this thesis, a physical axon (Paxon) potential generator was developed as a device to facilitate standardized comparisons of different electrodes. The Paxon generates repeatable, tuneable and physiological-like action potentials from a peripheral nerve. It consists of a testbed comprising 40 software controlled $20 \mu \mathrm{m}$ gold wires embedded in resin, each wire mimicking a node of Ranvier. ECG surface $\mathrm{Ag}-\mathrm{AgCl}$ electrodes were systematically tested with the Paxon. The results showed small variations in orientation (rotation) and position (relative to axon position) which directly impact the acquired signal. Other electrode types including DBS electrodes can also be evaluated with the Paxon.

A theoretical comparison of a single cable neuronal model with an alternative established double cable neuron model was completed. The output with regards to DBS was implemented to comparing the models. These models were configured to investigate electrode stimulation activity, and in turn to assess the activation distance by DBS for changes in axon diameter (1.5-10 $\mu \mathrm{m})$, pulse shape (rectangular biphasic and rectangular, triangular and sinus monophasic) and drive strength (1-5 V or mA). As both models present similar activation distances, sensitivity to input shape and computational time, the neuron model selection for DBS could be based on model complexity and axon diameter flexibility. An application of the in-house neuron model for multiple DBS lead designs, in a patient-specific simulation study, was completed. Assessments based on the electric field along multiple sample planes of axons support previous findings that a fixed electric field isolevel is sufficient for assessments of tissue activation distances for a predefined axon diameter and pulse width in DBS.
\end{abstract}




\begin{abstract}
Abstrakt
Elektroder används inom sjukvården, både för att mäta biologiska signaler, t.ex. hjärtats aktivitet med EKG, eller för att stimulera vävnad, t.ex. vid djup hjärnstimulering (DBS). För båda användningsområdena är det viktigt med en grundläggande förståelse av elektrodens interaktion med vävnaden. Det finns ingen standardiserad metod för att utvärdera medicinsk elektroders dataöverföringsfunktion. I den här avhandlingen presenteras en metod för att underlätta elektrodtestning. En hårdvarumodell av ett axon (Paxon) har utvecklats. Paxon kan programmeras för att efterlikna repeterbara aktionspotentialer från en perifer nerv. Längs axonet finns 40 noder, vilka var och en består av en tunn $(20 \mu \mathrm{m})$ guldtråd inbäddad i harts och därefter kopplad till elektronik. Denna testbädd har använts för att undersöka EKG elektroders egenskaper. EKG elektroderna visade på variationer i orientering och position i relation till Paxon. Detta har en direkt inverkan på den registrerade signalen. Även andra elektrotyper kan testas i Paxon, t.ex. DBS elektroder.
\end{abstract}

En teoretisk jämförelse mellan två neuronmodeller med olika komplexitet, anpassade för användning vid DBS studier, har utförts. Modellerna konfigurerades för att studera inverkan på aktiveringsavstånd från olika axondiametrar, stimulationspuls och stimulationsstyrka. Då båda modellerna visade likvärdiga aktiveringsavstånd och beräkningstid så förordas den enklare neuronmodellen för DBS simuleringar. En enklare modell kan lättare introduceras i klinisk verksamhet. Simuleringarna stöder tidigare resultat som visat att det elektriska fältet är en bra parameter för presentation av resultat vid simulering av DBS. Metoden exemplifieras vid simulering av aktiveringsavstånd och elektriska fältets utbredning för olika typer av DBS elektroder i en patient-specifik studie. 


\section{List of Publications}

The following publications, referred to by Roman numerals, are included in this thesis:

I. Malcolm A. Latorre, Adrian D.C. Chan, Karin Wårdell (2015) A Physical Action Potential Generator: Design, Implementation and Evaluation, Frontiers in Neuroscience, Vol. 9, 1-11 p., 371

II. Malcolm A. Latorre, E. Göran Salerud, Karin Wårdell (2016) Describing Measurement Behaviour of a Surface $\mathrm{Ag}-\mathrm{AgCl}$ Electrode Using the Paxon Test Platform, XIV Mediterranean Conference on Medical and Biological Engineering and Computing 2016, IFMBE Proceedings, SPRINGER, Vol. 57, 442-445 p

III. Fabiola Alonso, Malcolm A. Latorre, Nathanael Göransson, Peter Zsigmond, Karin Wårdell (2016) Investigation into Deep Brain Stimulation Lead Designs: a Patientspecific Simulation Study, Brain Science, Vol 6, Issue3 pp1-16

IV. Malcolm A. Latorre, Christian Schmidt, Ursula van Rienen, Karin Wårdell (2017) A Comparison between Single and Double Cable Neuron Models Applicable to Deep Brain Stimulation, submitted

Related Publications

Malcolm Latorre (2015) Action Potential Generator and Electrode Testing, Linköping: Linköping University Electronic Press, 2015, 44 p. Thesis Number 1725, ISBN: 978-91-7685974-2 (print, Licentiate in Engineering)

Fabiola Alonso, Malcolm Latorre, Karin Wårdell (2015) Comparison of Three Deep Brain Stimulation Lead Designs under Voltage and Current Modes, World Congress on Medical Physics and Biomedical Engineering, June 7-12, 2015, Toronto, Canada, Vol. 51, pp 1196 1199 (oral)

Fabiola Alonso, Malcolm Latorre, Karin Wårdell (2015) Neural Activation Compared to Electric Field Extension of Three DBS Lead Designs, 7TH INTERNATIONAL IEEE/EMBS CONFERENCE ON NEURAL ENGINEERING, Montpellier, April 22-24 (poster)

Malcolm Latorre, Adrian D.C.Chan, Karin Wårdell (2015), An Axon Mimic for Medical Electrode Tests, IUPESM 2015 World Congress on Medical Physics \& Biomedical Engineering, Canada, June 7-12 2015 (oral)

Malcolm Latorre, Adrian D.C.Chan, Karin Wårdell (2014) PAXON: The Physical Axon Model, MTD Gothenburg, Sweden, 14-16 October 2014 (poster)

Malcolm Latorre, Adrian D.C.Chan, Karin Wårdell (2013) The Paxon - A Physical Axonal Mimic, 2013 IEEE EMBS Conference on Neural Engineering (NER), San Diego, USA, Nov. $6-72013$ (poster) 
Malcolm A. Latorre, Rejean Munger, Adrian D.C. Chan, Karin Wårdell (2010) The Paxon: An Electro-physical Model of a Myelinated Axon, World Congress of NeuroTechnology, Rome, 11-14 October 2010 (oral) 


\section{Acknowledgement}

I would like to thank my supervisors Karin Wårdell and Göran Salerud for their support, encouragement throughout this process, and for the many and varied conversations that inspired thought and progress in this and other projects.

I would like to acknowledge the Swedish Research Council Grant No. 621-2013-6078 and 2016-03564, Linköping University's faculty grant, and the Swedish Foundation for Strategic Research BD15-0032 which have all funded parts of this research.

Thanks also goes to Bengt Ragnemalm, research engineer at IMT for his support and direction with microcontrollers. Without his suggestions, this work would have been purely in the domain of mixed signal circuits and analog computers. I also thank Meagan Latorre for her help with some of the figures used in this work.

August 2017, Linköping

Malcolm Latorre 


\section{Abbreviations}

3D three dimension

AC alternating current

ADP adenosine diphosphate

$\mathrm{Ag} \quad$ silver

$\mathrm{Ag}-\mathrm{AgCl}$ silver silver-chloride electrode

AP action potential

ATP adenosine triphosphate

$\mathrm{Au} \quad$ gold

AWG American wire gauge

BCI brain computer interface

$\mathrm{C} \quad \mathrm{C}$ programming language

$\mathrm{Ca}^{2+} \quad$ calcium

$\mathrm{Cl}^{-} \quad$ chloride

$\mathrm{Cm}$ membrane capacitance

CMOS complementary metal oxide semiconductor

$\mathrm{Cu} \quad$ copper

DBS Deep brain stimulation

DC direct current

DUT device under test

ECG/EKG electro cardiogram

ECoG ElectroCorteogram

EEG electroencephalogram

EMG electromyogram

ENG electroneurogram

EOG electrooculogram

ERG electroretinogram

FDA food and drug administration

FPGA field programmable gate array

G membrane conductivity

$\bar{g}_{\mathrm{K}} \quad$ potassium channel conductivity

$\bar{g} l \quad$ leakage conductivity

$\bar{g}_{\mathrm{Na}} \quad$ sodium channel conductivity

$\mathrm{h} \quad \mathrm{Na}+$ blocking function

$\mathrm{H}-\mathrm{H} \quad$ Hodgkin and Huxley

$\mathrm{Hz} \quad$ hertz (unit s-1)

$\mathrm{I} / \mathrm{O} \quad$ input/output bidirectional control line

IC integrated circuit

IDC insulation-displacement contact

IPG implantable pulse generator

Ir iridium

IR infrared

$\mathrm{K}^{+} \quad$ potassium

$\mathrm{m} \quad \mathrm{Na}+$ activating function

MER Microelectrode recording

$\mathrm{n} \quad \mathrm{K}+$ activating function

$\mathrm{Na}^{+} \quad$ sodium

$\mathrm{NaCl}$ sodium chloride (salt)

NAND inverted output logical AND gate 


$\begin{array}{ll}\text { PEDOT } & \text { poly 3,4-ethylenedioxythiophene } \\ \sigma(\mathrm{Phi}) & \text { propagation velocity } \\ \mathrm{PMMA} & \text { Poly(methyl methacrylate) also known as ( acrylic plastic) } \\ \mathrm{Pt} & \text { platinum } \\ \mathrm{R}_{2} & \text { axoplasm resistance } \\ \text { TENS } & \text { transcutaneous electric nerve stimulator } \\ \mathrm{TTL} & \text { transistor transistor logic } \\ \mu \mathrm{P} & \text { microcontroller / microprocessor } \\ \mathrm{USB} & \text { universal serial bus } \\ \mathrm{V}_{\mathrm{Cl}} & \text { chlorine Nernst half-cell potential } \\ \mathrm{VIM} & \text { ventral intermediate nucleus } \\ \mathrm{V}_{\mathrm{K}} & \text { potassium Nernst half-cell potential } \\ \mathrm{V}_{\mathrm{l}} & \text { leakage potential } \\ \mathrm{V}_{\mathrm{m}} & \text { membrane potential } \\ \mathrm{V}_{\mathrm{Na}} & \text { sodium Nernst half-cell potential } \\ \mathrm{ZI} & \text { zona incerta }\end{array}$




\section{Table of Contents}

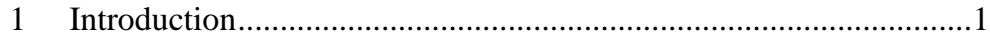

1.1 Historical Aspects of Biopotentials ..........................................2

2 The Nerve Cell .............................................................................

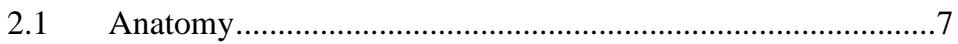

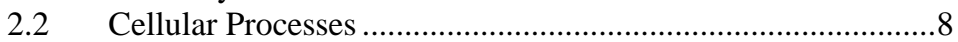

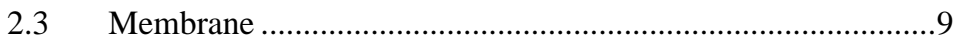

2.4 Static Transmembrane Potential ..........................................10

2.5 Action Potential and the Dynamic Membrane.......................12

2.6 Synthetic Triggering of an Action Potential from the Axon..15

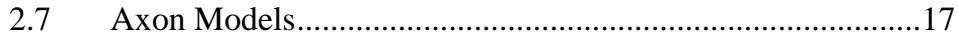

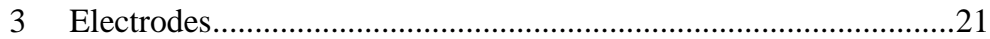

3.1 Design and Construction........................................................21

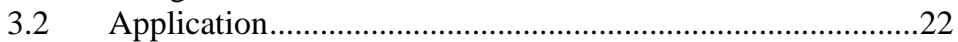

3.3 The Ideal Model for Electrode Testing .................................24

3.4 The Tissue-Electrode Interface ..............................................27

3.5 The Need for a Common Electrode Test Platform ...............29

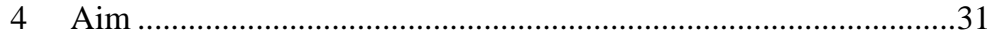

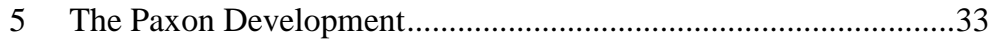

5.1 Test Well Construction .............................................................34

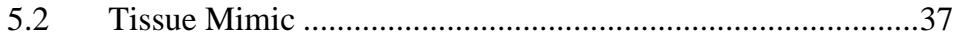

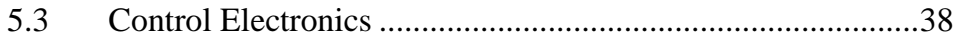

5.4 Data Capture and Processing ...................................................42

6 Electrode Evaluation: FDA vs Paxon ..............................................47

7 Computational Neuron Models Applied to DBS .............................51

7.1 Application Study with Patient Specific Data ........................51

7.2 Neuron Computational Model Comparison...........................55

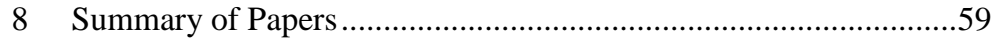

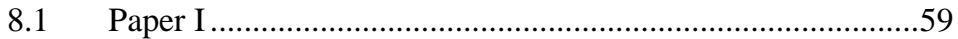

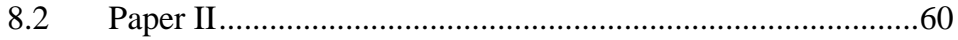

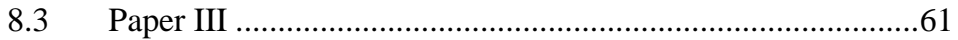

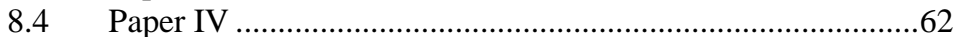

9 Discussion and Conclusions ......................................................6

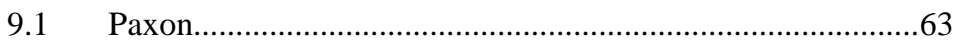

9.2 General Electrode Evaluations using the Paxon ....................65

9.3 Neuron Model Evaluations ....................................................66

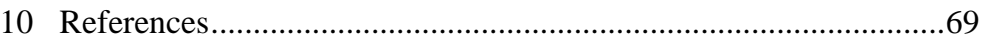




\section{Introduction}

Clinical diagnostics based on the body's biopotentials are very useful tools. Current technology for biopotential recording is advanced and able to aid in the assessment of disorders to a great degree. As an example, an electrocardiogram (ECG) is used to record the electrical signals from the heart, and based on these recordings, assessments and treatments can be prescribed. Figure 1a shows ECG equipment that was used in the 1940's to acquire the cardiac signal. This unit was deemed portable although it required an external power source, weighing $17 \mathrm{~kg}$ and was limited to three lead recordings. Presently, the state of the art, diagnostic capable, 12 lead battery-operated hand-held ECG device weighing about $1 \mathrm{~kg}$ is shown for comparison (Figure $1 \mathrm{~b}$ ).

a

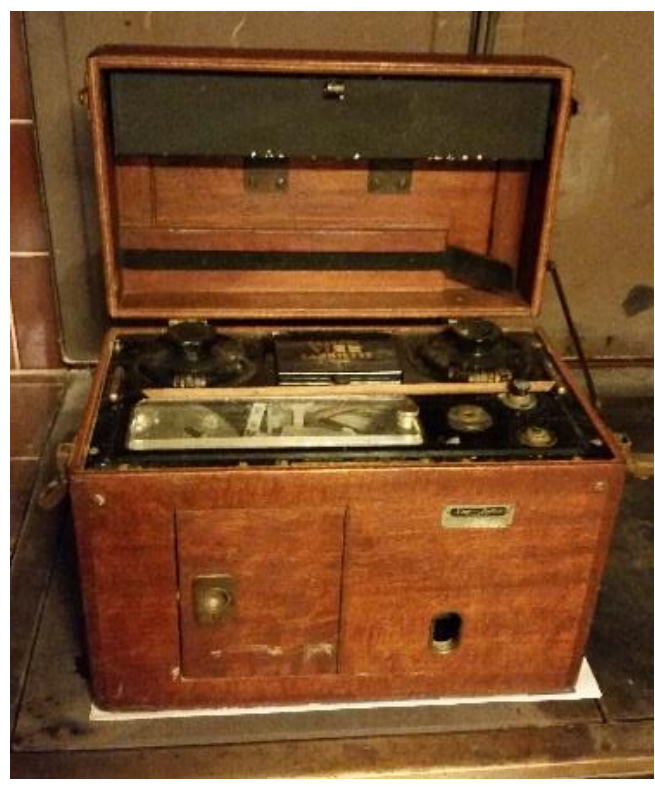

b

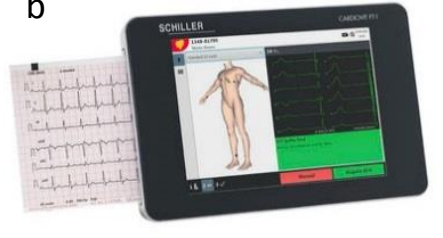

Figure 1. (a) 1940's production "portable" 3 lead ECG by Sanborn Cardiette Model 51 vacuum tube electronics with accessories, note "bulb" electrodes (images from author's private collection). (b) Modern portable ECG recorder, 12 lead, with placement chard on screen model CARDIOVIT MS-2015 [1] 
Understanding and controlling the body's biopotential flows, are challenging problems that are actively being investigated by many research groups today. From an engineering viewpoint, the body can be described by purely mechanical (statics and dynamics, pressures and flows), chemical, or electrical means, depending on what is to be explored. Such descriptions are models that define the function of one aspect of a system in a constrained way. A model presents a simplified working version of the larger more complex system that describes its functions. Model simplifications restrict how applicable the model is to reality. A definition for "model" that fits this understanding is "A systematic description of an object or phenomenon that shares important characteristics with the object or phenomenon. Scientific models can be material, visual, mathematical, or computational and are often used in the construction of scientific theories" [2]. In this thesis, both software (computational) and hardware (material) models are employed in the investigation of neuron electrode interfaces for recording and stimulation events.

\subsection{Historical Aspects of Biopotentials}

The earliest references investigating biopotentials or "animal electricity" date back to 1664 when Jan Swammerdam investigated the volumetric changes within muscles during contraction [3]. Interestingly these are events of stimulation but not signal detection. Around 1745, Laura Bassi and Gioseppe Veratti also examined the medical applications of electrostatic machines, although details of Bassi's contributions to this area of research were not published by her [4]. By the 1790's Luigi Galvani's "animal electricity" experiments were well-documented, and led to many more studies into electricity and biological electrical activity [5], (Figure 2).

The "frog's leg preparation" has been used many times in research. The minimal preparation comprises the muscle belly and connecting sciatic nerve, while more complete configurations involve the complete leg (Figure 2). The sciatic nerve is a large nerve bundle composed of multiple fibrils that attach to multiple muscle spindles. This nerve was used in very early bioelectric experiments. The knowledge of the "nerve" has continued to grow from these very early ideas to the extremely complex models that are available today [6]. 
These early investigator contributions are the foundation that allow use of the body's electrical signalling for diagnostic purposes. However, fundamental questions remain, e.g. are the measured signals correct or accurate enough? Electrodes that are used to couple the biological circuits to the electronic circuits have also undergone continuous development. Figure 3 shows an early ECG machine that includes the earliest electrodes implemented with containers of saline solution to aid in signal coupling [7]. Figure 4 shows some clinical skin surface electrodes from different times including the current state-ofthe-art.

Another type of clinical electrode is used for deep brain stimulation (DBS). This is a technology developed for patients afflicted by the symptoms from movement disorders such as Parkinson's disease. This neurodegenerative disorder has been diagnosed in approximately 6.3 million people worldwide [9]. The design of DBS electrodes to affect the treatments is an area of intense research [10]. Examples of two commercially available DBS electrodes are presented in Figure 5. Other examples of biological interface electrodes and systems are those for retinal prostheses that is being developed to provide digital camera image information to the nerve structure of the retina [11]. The current state of the art implant, the "Argus II retinal prosthesis" [12] consists of 60 microelectrodes controlled by a set of lead-in wires attaching it to an external processor and a "glasses mounted" camera. These are two well-known applications of electrode technology that interact with the body's biopotential for clinical use. 


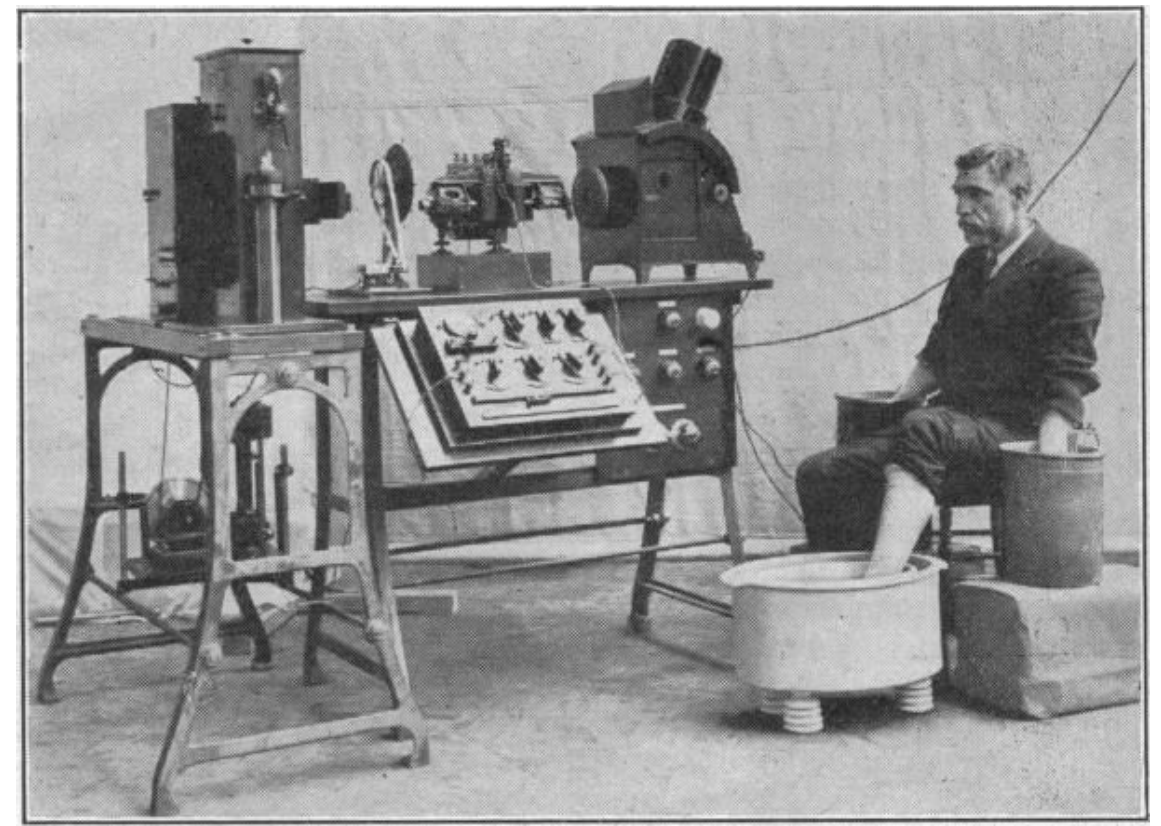

Figure 3. A Cambridge Scientific Instrument Company commercial ECG machine from around 1911 for producing human electrocardiograms according to the standards developed by Einthoven. The electrodes are containers of salt solution. Reproduced from BMJ, [13] with permission from BMJ Publishing Group Ltd.
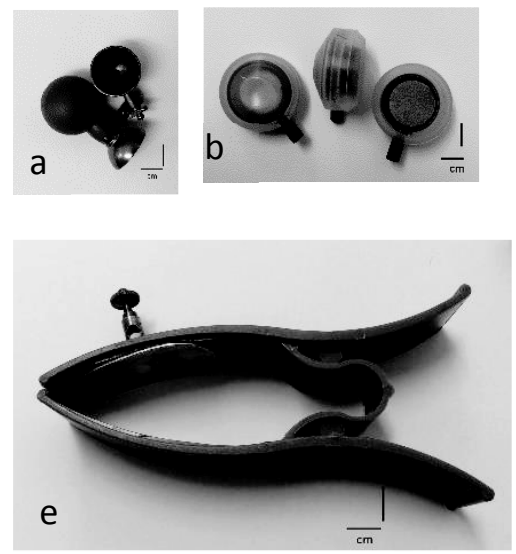
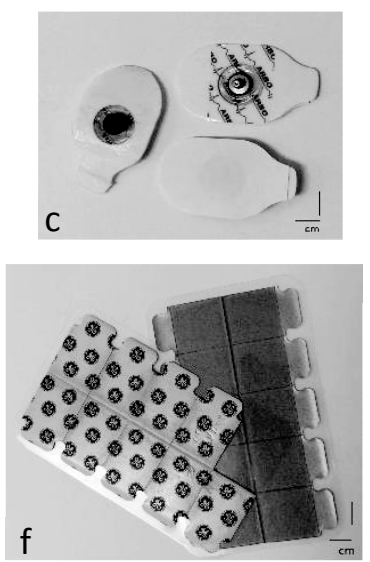

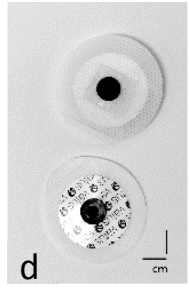

Figure 4. Examples of surface electrodes (a) early suction cup design, (b) modern suction cup design, (c) self-adhering with conductive gel and metal button, (d) self-adhering with conductive gel and metal button, (e) arm clamp design, (f) self-adhering with conductive adhesive and conductive backing, photos from available equipment. Bar $1 \mathrm{~cm}$. 


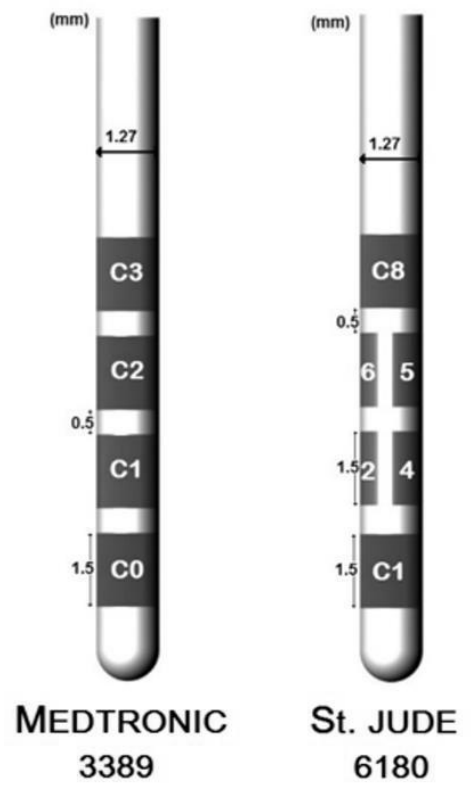

Figure 5. Two examples of clinically accessible leads for deep brain stimulation. Permission granted for modified image originally published in Brain Science PAPER III. 


\section{The Nerve Cell}

\subsection{Anatomy}

Nerve cells form the electrical connections that the body uses for transmitting signals quickly from one location to another. They are classified into three groups based on function: sensory neurons, motor neurons, and interneurons [14]. Sensory neurons are a subgroup of the afferent nervous system which carries information from the body's peripheral sensors to the central nervous system for perception and motor coordination. Motor neurons form the efferent system which carries commands from the brain or spinal cord to muscles or glands. Interneurons are the most common and are classed into relay and local types. Relay interneurons have long axons and convey signals from one brain region to another, while local interneurons have short axons that connect with nearby neurons forming local circuits [14].

Peripheral nerve fibres are grouped into two major classes, myelinated and non-myelinated. The myelinated fibres are split into two subgroups, A and B fibres, based on speed of propagation, and other detail of the nerve function with relation to action potential (AP) duration and form, specifically the refractory period and chronaxie properties [15].

The commonly represented nerve cell or neuron (Figure 6) comprises four main regions: the dendrites, the cell body, the axon and the terminals. The dendritic tree is a process extending from the cell body with a branching structure. This is where the chemical receptors that start the membrane modulation are located and is also the initiating source of an AP. The cell body, or soma, is where the nucleus and main components of the cell reside. Within the soma, the ripple-like pattern of the AP travels along the membrane. The ripple is concentrated at the axonal hillock, which, is a necking down of the cell wall. The axonal hillock narrows down to the axonal process, or axon. The axon can be a long extension from the cell body, ranging from $0.1 \mathrm{~mm}$ to $2 \mathrm{~m}$ or more, where the AP signal propagates from one end to the other [14]. At the far (distal) end of the axonal process are the synaptic terminals, which are varied. The common feature is that they conduct electrical signals to the nerve synapses (gaps between two adjacent nerves). The synaptic gap is bridged through the release of electrochemical neurotransmitters. 
The unmyelinated axon has a similar structure to the myelinated axon, but without the myelin that is formed by the Schwann cells in the peripheral system. Schwann cells are "helper" cells that wrap around the axon in segments along its length. The gaps in the myelin are called the nodes of Ranvier.

Nerve tissue in the central nervous system is also divided into two

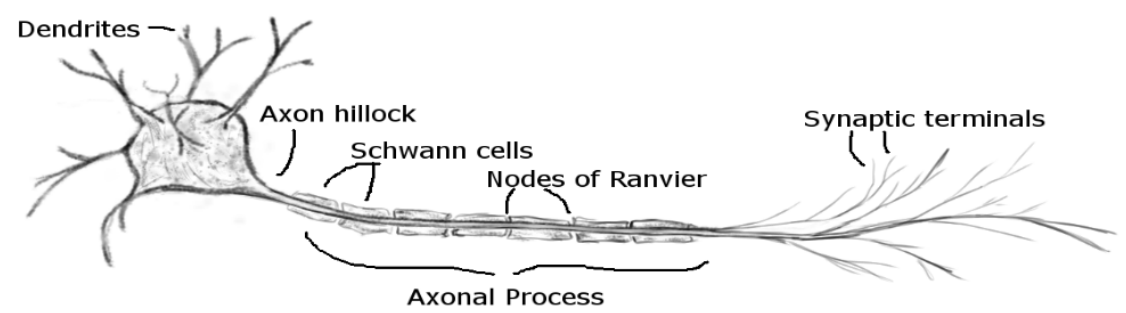

Figure 6. Structure of a myelinated neuron listing the external features. A typical nerve has a long axon, cell body in the middle, with a large branching dendritic trees [8].

types, neurons and neuronglia. In the brain and spinal cord, tissues are mainly grouped into white matter and grey matter. The white matter is mainly comprised of myelinated nerves fibres, predominately axons, and cell body, while the grey matter is mainly comprised of the cell bodies of the nerves, unmyelinated axons, synaptic terminals and cell dendrites. White matter describes axons that signal over long distances, and grey matter typically forms the processing elements.

\subsection{Cellular Processes}

The active biological processes occurring within all living cells, including nerves, are driven by energy. That energy comes in the form of adenosine triphosphate (ATP). ATP is formed by the oxidation of sugars within the cell, or the conversion of adenosine diphosphate (ADP) into ATP, and is called cellular respiration [15]. ATP is the energy source that drives active processes such as ion pumps in nerve cells (Figure 7 - right side of image) and muscle "bond-cleave" actions when a muscle is actuated. In the nerve cell, ionic pumps consume ATP and are the principle mechanism by which the concentration gradient of ions across 
the cell membrane is kept. When ATP is consumed, the result is ADP, water and energy.

All living cells have a transmembrane potential, which, is a voltage that can be measured between the inside and outside of the cell membrane due to a difference in ion concentrations. For the nerve cell, active pumping moves sodium $\left(\mathrm{Na}^{+}\right)$out of the cell and potassium $\left(\mathrm{K}^{+}\right)$ into the cell. Not all cells, however, are electrically active. The ability to actively change their membrane potential is limited to nerve cells, muscle cells and a few highly specialized cells.

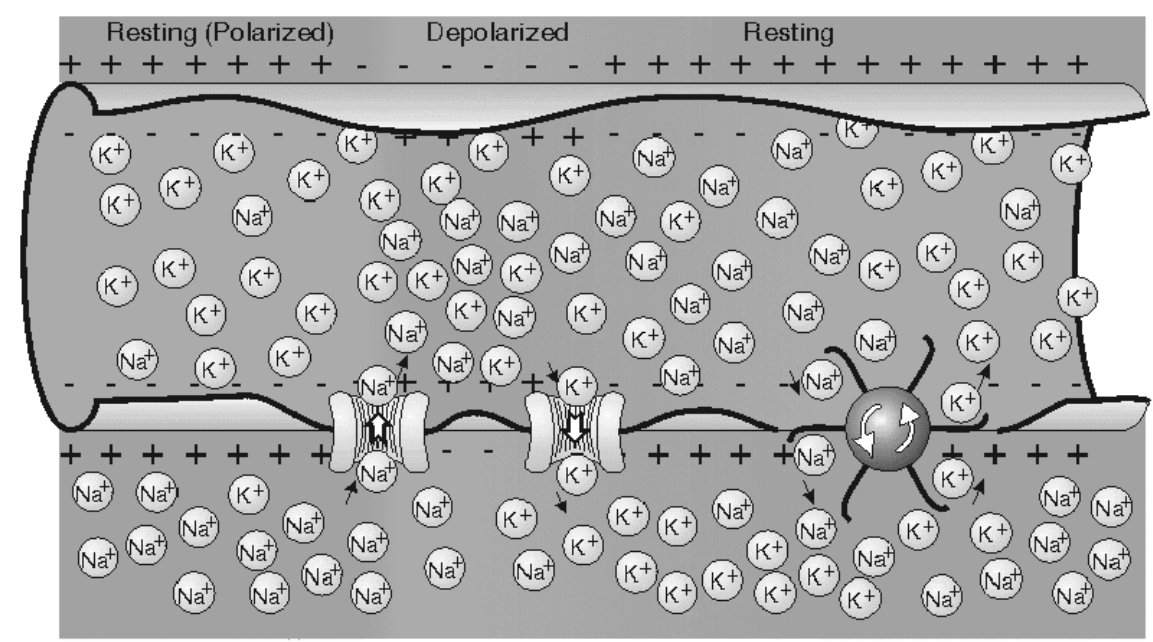

Figure 7. Functional drawing of ion channels and an ion pump that perforate the bilipid cellular membrane of a cell. Reproduced with permission from Malmivuo and Plonsey [16].

\subsection{Membrane}

As with other cells, the cell or plasma membrane of neurons comprise a phospholipid bilayer that regulates entry and exit of substances. The neuronal plasma membrane, however, is electrically excitable. Voltage gradients are maintained across these membranes by means of metabolically driven ion pumps, which combine with ion channels embedded within the membrane to generate intracellularversus-extracellular concentration differences of ions such as $\mathrm{Na}^{+}, \mathrm{K}^{+}$, chloride $\left(\mathrm{Cl}^{-}\right)$and calcium $\left(\mathrm{Ca}^{2+}\right)$ (Figure 7$)$. In an unmyelinated axon, 
these channels are distributed throughout the entire cell wall. For myelinated axons, there are some specific channels that are distributed throughout, e.g. $\mathrm{Ca}^{2+}$, while others are concentrated at the nodes of Ranvier, e.g. $\mathrm{Na}^{+}$and $\mathrm{K}^{+}$. These passages are protein structure elements that include both ion channels, and ion pumps.

A myelinated nerve is not a single cell. Glial cells are involved, specifically the neurolemmocytes, also known as Schwann cells, that are the source of the myelin in the peripheral nervous system (Figure 6). These cells function by wrapping themselves around nerve fibres and forming a leaky insulating layer (Figure 8). Myelinated nerves are found throughout the body, and there are some specialized axon-myelin configurations [17].

For the physical axon model (Paxon) developed, Paper I focuses on the nerve fibres commonly found in the peripheral nervous system, consideration was only given to the effects at the node of Ranvier. The nerve model used to study stimulation effects on brain tissue, included modeling of the node of Ranvier as well as the myelinated segment.

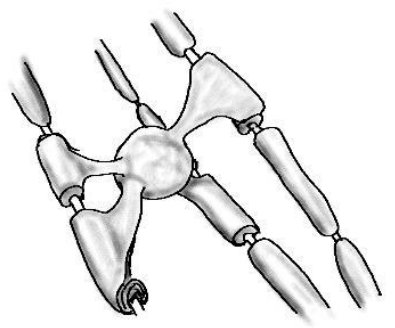

Figure 8. Image of myelin around structure axons extending from a from Schwan cell.

\subsection{Static Transmembrane Potential}

Active ion pumps move $\mathrm{Na}^{+}$out of and $\mathrm{K}^{+}$into the nerve cell. The transmembrane gradient of ion concentration results in a transmembrane potential that is, by convention, measured with the zero reference on the outside of the cell wall. Directly applying the Nernst equation (Eq. 1) to each of the ion species and their concentrations on either side of the membrane wall and summing each ion's contribution results in the "resting potential" of the membrane as presented in Eq. 1. 


$$
E=\frac{R T}{z F} \ln \frac{C_{o}}{C_{i}}
$$

Where:

$\begin{array}{ll}E & \text { Nernst potential }(\mathrm{V}) \\ R & \begin{array}{l}\text { Universal gas constant }(1.98 \text { Calories/mole Kelvin) or } \\ \left(8.314 \mathrm{~J} /\left(\mathrm{mol}{ }^{\circ} \mathrm{K}\right)\right)\end{array} \\ T & \begin{array}{l}\text { Temperature }\left({ }^{\circ} \mathrm{K}\right) \\ \text { charge on the ion }\end{array} \\ z & \quad \text { Faraday's Constant }(2.3 \times 104 \text { calories per mole } \mathrm{V}) \text { or } \\ F & (96485 \mathrm{C} / \mathrm{mol}) \\ C_{o} & \text { ion concentration outside cell (m mole) } \\ C_{i} & \text { ion concentration inside cell (m mole) }\end{array}$

Applying Eq. 1 to each of the contributing ion species for the nerve cell result in the Goldman-Hodgkin-Katz equation (Eq. 2).

$$
V_{m}=\frac{R T}{F} \ln \left(\frac{p_{K}\left[K^{+}\right]_{o}+p_{N a}\left[N a^{+}\right]_{o}+p_{C l}\left[C l^{-}\right]_{i}}{p_{K}\left[K^{+}\right]_{i}+p_{N a}\left[N a^{+}\right]_{i}+p_{C l}\left[C l^{-}\right]_{o}}\right)
$$

Where:

$\begin{array}{ll}V_{m} & \text { Membrane potential }(\mathrm{V}) \\ p_{K} & \mathrm{~K}^{+} \text {membrane permeability }\left(\mathrm{N} / \mathrm{A}^{2}\right) \\ p_{\mathrm{Na}} & \mathrm{Na}^{+} \text {membrane permeability }\left(\mathrm{N} / \mathrm{A}^{2}\right) \\ p_{\mathrm{Cl}} & \mathrm{Cl}^{-} \text {membrane permeability }\left(\mathrm{N} / \mathrm{A}^{2}\right) \\ {\left[\mathrm{K}^{+}\right]_{o}} & \mathrm{~K}^{+} \text {ion concentration outside cell (mole) } \\ {\left[\mathrm{K}^{+}\right]_{i}} & \mathrm{~K}^{+} \text {ion concentration inside cell (mole) } \\ {\left[\mathrm{Na}^{+}\right]_{o}} & \mathrm{Na}^{+} \text {ion concentration outside cell (mole) } \\ {\left[\mathrm{Na}^{+}\right]_{i}} & \mathrm{Na} \text { ion concentration inside cell (mole) } \\ {\left[\mathrm{Cl}^{-}\right]_{o}} & \mathrm{Cl} \text { ion concentration outside cell (mole) } \\ {\left[\mathrm{Cl}^{-}\right]_{i}} & \mathrm{Cl} \text { ion concentration inside cell (mole) }\end{array}$

The values of permeability for a nerve membrane at rest can also be applied as a ratio where $p_{K}$ being the highest is set to 1 , the ratios then 
become $p_{K}: p_{\mathrm{Na}}: p_{\mathrm{Cl}}=1: 0.05: 0.45$. For a human peripheral myelinated nerve, the resulting rest potential is $\sim-70 \mathrm{mV}$. The resting potential is reached when the ion pumps balance the ion leakage, or leakage current [18]. There are other ions that move across the membrane, but their contribution is not directly to the AP.

Until the experimental studies by Hodgkin and Huxley $(\mathrm{H}-\mathrm{H})$, the actual mechanism of an AP were unknown although there were a number of hypotheses $[8,19,20]$. Isolating each of the ion channels with chemical inhibitors, and applying the techniques of voltage and current clamping $\mathrm{H}-\mathrm{H}$ were able to measure the isolated and independent ionic currents based on membrane potential, and vice a versa [18]. The paddle wheel in Figure 7 represents the $\mathrm{Na}^{+} \mathrm{K}^{+}$pump active process, and the tubes to the left represent the active ion channels.

\subsection{Action Potential and the Dynamic Membrane}

An AP wave (Figure 9) has distinctly named phases. The steady state level when the nerve is not "active" is called the resting state. In the resting state, the transmembrane potential stays around $-70 \mathrm{mV}$ referenced to the outer membrane wall. The threshold voltage for mammalian peripheral nerve cells is approximately $-56 \mathrm{mV}$. If the transmembrane potential is not discharged to the threshold voltage, no AP is triggered and no avalanche process takes place. The depolarizing phase is the first segment of an AP, and takes place after the threshold potential is reached. This is when the membrane discharges due to the influx of $\mathrm{Na}^{+}$ions flowing through the $\mathrm{Na}^{+}$channels in the membrane. The transmembrane potential rises from around $-70 \mathrm{mV}$ to around +30 $\mathrm{mV}$ in this phase. The repolarization phase takes place when the $\mathrm{Na}^{+}$ channels start closing, and the $\mathrm{K}^{+}$ion channels start opening, e.g. $\mathrm{K}^{+}$ efflux starts. The transmembrane potential in this phase drops back to the resting potential. Classical understanding of the ion channels are based on the Hodgkin and Huxley model. This model demonstrates that at the end of the repolarising phase, the $\mathrm{Na}^{+}$channels are closed, but the $\mathrm{K}^{+}$ channels are still open and just starting to close. Due to the open $\mathrm{K}^{+}$ion channels, the transmembrane potential continues to drop below the resting potential. This is the hyperpolarization phase, or refractory period. In this phase, the transmembrane potential dips to approximately $-90 \mathrm{mV}$. This voltage level also coincides with the Nernst potential for $\mathrm{K}^{+}$ion gradient across the membrane. Figure 10 presents the mechanisms by 
which the transmembrane potentials are changing in time based on the membrane conductivity $(\mathrm{G})$ to specific ions. This change in potential at one node of Ranvier is "electrically" coupled to its neighbouring nodes of Ranvier, and it is this coupling that pulls the following node of Ranvier to depolarize above the threshold level. This process is repeated along the axon length.

The refractory period is also broken down into two parts, the absolute refractory period, which is linked to the $\mathrm{Na}^{+}$channel activation and following inactivation time, and the relative refractory period which occurs once the $\mathrm{Na}^{+}$channels have reset, but before the $\mathrm{K}^{+}$channels have fully closed (Figure 10) [15]. During the absolute refractory period, an AP cannot be re-triggered, while during the relative refractory period, an AP can be re-triggered although the threshold potential is much higher. The high threshold returns to its typical level as the transmembrane potential returns to its resting potential [15].

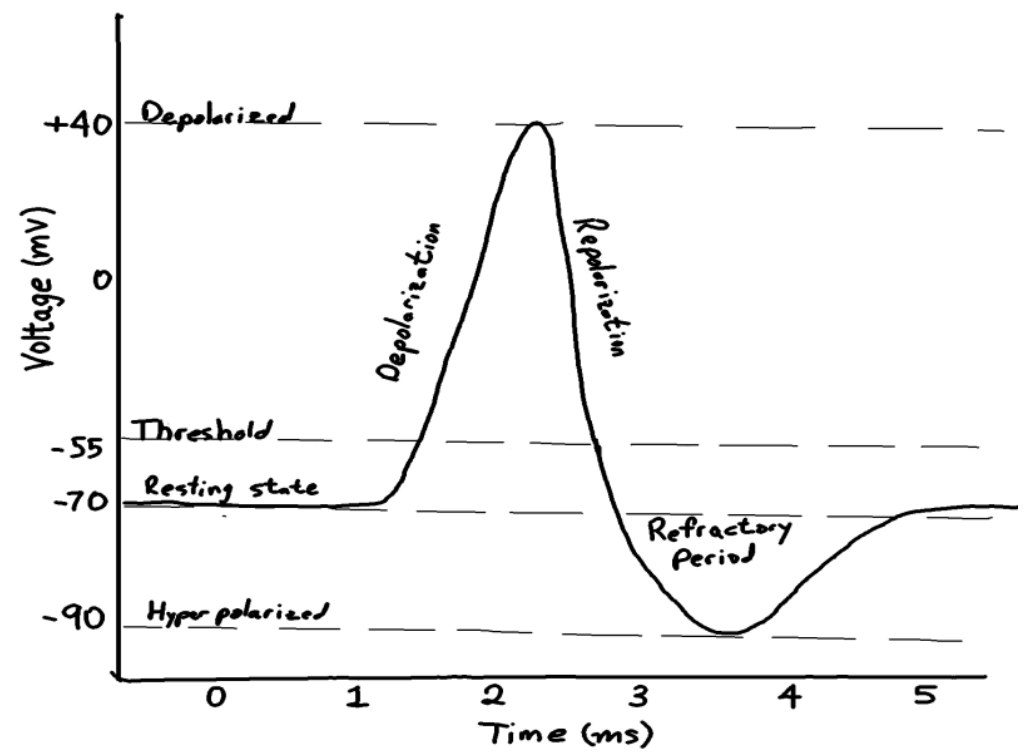

Figure 9. Typical membrane potentials and phases of an action potential. 


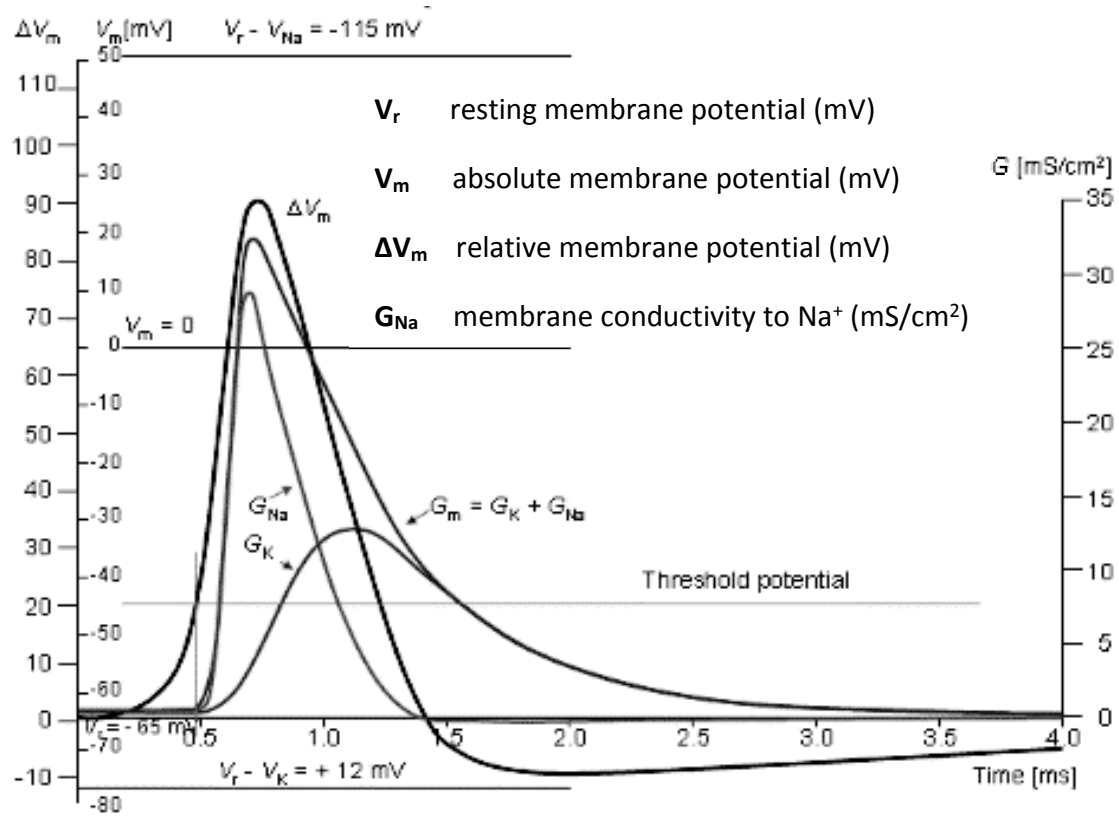

Figure 10. Individual transmembrane conductance and potentials that together for an AP with permission from Malmivuo and Plonsey [16].

The shape of the first part of an AP is depicted as a smooth transition from resting potential up to the maximum (Figure 9). This is caused by the summation of the individual ion channels turning on. If all ion channels at a node of Ranvier activated simultaneously, then the wave shape would be digital in nature, ON / OFF. Not all ion channels turn on at the same threshold. Hodgkin and Huxley found that the voltage gating of the ion channels have a statistical probability of opening and closing at a specific voltage, and that the ion channels were more than single gated. For example, the $\mathrm{Na}^{+}$channel has three fast activating gates $(m)$ that all must be open for the channel to conduct, but only one slow gate (h) to stop the current. Likewise the $\mathrm{K}^{+}$channel has 4 individual slower activating gates $(n)$ and no inhibiting gate. Lastly all activation gates must be open for the ion channel to conduct, with the $n$ and $m$ gates having a probability of being open at a specific electric potential.

Figure 11 shows the electrical potential at various locations along the neural circuit. Of interest is the nerve impulse, which is in the far right of the plot. Any sub-threshold membrane depolarization will not cause 
the "regeneration" of the AP at that location (node of Ranvier), and the signal will not propagate if the subthreshold trigger is left to decay back to resting potential. A subthreshold impulse that repeats faster than the membrane wall can discharge, will "integrate" and eventually trigger an AP. Also of significance is that the amplitude of the AP on the cell body, and axonal hillock are not of high enough amplitude to trigger and AP. Assuming that the ionic current in the membrane is constant (per unit area), by applying Ohm's law, the voltage generated at a small distance is therefore related to the impedance of the axoplasm and exoplasm. In the cell body, there is a large axoplasm surface area and short distances. Therefore, the path that the current (ions) takes has a low impedance that results in a low voltage. At the axonal hillock, the current must pass through a decreasing cross-sectional surface area but it is still a relatively short distance (incrementally increasing impedance). This results in an incrementally higher voltage as the hillock necks down to the axon diameter. The voltage close to the soma is too low to trigger an AP, but as the diameter reduces to the axon diameter, the threshold is passed and the membrane is depolarized enough to form a propagating AP. Finally, in a myelinated axon, the surface area is small relative to the previous two cases. The myelin forces the current to pass a longer distance, resulting in a higher impedance and voltage and effectively faster propagation rates (Figure 11).

\subsection{Synthetic Triggering of an Action Potential from the Axon}

An AP can be triggered in a number of ways. The event that occurs at the synaptic gap is an electrochemical process, but the trigger can be purely physical/mechanical. For example, the pressure exerted on the ulnar nerve at the elbow has demonstrated that physical compression can trigger an AP that leaves the fingers feeling all tingly. 


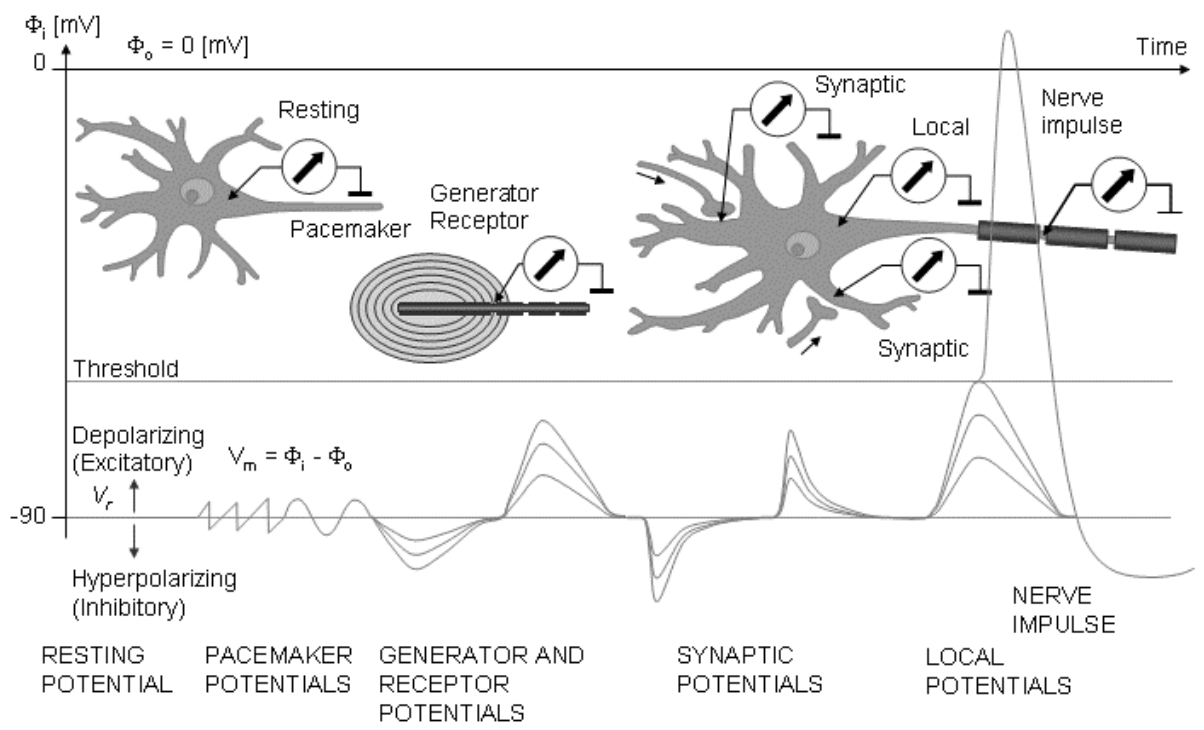

Figure 11. Action potentials at different sites along the nerve cell. The potential plot at the bottom of the figure shows the expected action potential. Reproduced with permission from Malmivuo and Plonsey [16]

Mechanisms that can be used to synthetically trigger an AP along an axon include electrical, optical, mechanical, magnetic, and chemical ones. Electrical stimulation is by far the most common and is exploited clinically e.g. DBS [21, 22], pacemakers [23-25], vagal nerve stimulation [26], transcutaneous electric nerve stimulation (TENS) [27, 28] and cochlear implants [29]. Optical methods reported include both unmodified nerve cells stimulated by near- to mid-IR (>1400 nm) [30, 31] and genetically modified nerve cells through optogenetics [32]. Mechanical stimulation can be either direct compression, as in the above example of the ulnar nerve pinch, mechanical irritation of the nerve [33], or by the use of ultrasound [34, 35]. Magnetic fields that are strong enough can also trigger an AP. This technique can be used to "stimulate" regions of the brain or visual cortex $[16,36]$. Magnetic triggering of nerves also accounts for the sensations of vibration and twitching of the extremities when in a high field strength MRI scanner. Finally, chemical triggering of the axon can also be achieved [37].

The effect of an external electrical field on a node of Ranvier is similar to that of the biological operation of an AP on a node of Ranvier. 
The difference is that with an externally applied field, there is the possibility of subthreshold stimulation which does not result in an AP, but, for a short time makes the nerve more sensitive to triggering, graded potentials (Figure 11) [16, 10, 17, 38].

\subsection{Axon Models}

\subsubsection{Test Signal Generation}

The $\mathrm{H}-\mathrm{H}$ model (as mentioned above in section 2.5) is a mathematical model that is described in Eq. 3 and Eq. 4. These equations of ion channel function are based on a series of experiments performed on a squid giant axon $[18,8]$. This statistical model has been the basis for many theoretical studies into the function of the axonal process (PAPER I, [39]) From the $\mathrm{H}-\mathrm{H}$ model, if the internal and external ion concentrations as well as the temperature are known then the transmembrane potential at any point along the axon can be calculated at any time through the AP curve according to Eq. 3.

$$
\begin{aligned}
\frac{d^{2} V}{d t^{2}}=\mathrm{k}\left(\frac{d V}{d t}\right. & +\frac{1}{C_{M}}\left(\bar{g}_{K} n^{4}\left(V-V_{K}\right)\right. \\
& +\bar{g}_{N a} m^{3} h\left(V-V_{N a}\right) \\
& \left.\left.+\bar{g}_{l}\left(V-V_{l}\right)\right)\right)
\end{aligned}
$$

\begin{tabular}{|c|c|}
\hline$\frac{a v}{d t^{2}}$ & second time derivative of the voltage $(\mathrm{V})$ \\
\hline$V$ & transmembrane voltage $(\mathrm{V})$ \\
\hline$V_{K}, V_{N a}, V_{l}$ & Nernst' s voltage for $\mathrm{K}^{+}, \mathrm{Na}^{+}$and leakage ions $(\mathrm{V})$ \\
\hline $\begin{array}{l}\bar{g}_{K}, \bar{g}_{N a}, \bar{g}_{l} \\
C_{M}\end{array}$ & $\begin{array}{l}\mathrm{K}^{+}, \mathrm{Na}^{+} \text {, and leakage; maximum conductivity / area }\left(\mathrm{S} / \mathrm{m}^{2}\right) \\
\text { membrane capacitance per unit area }\left(\mathrm{F} / \mathrm{m}^{2}\right)\end{array}$ \\
\hline & activating function of the ion channel \\
\hline
\end{tabular}

Where: 
Where the axon property constant $\mathrm{k}\left((\Omega \mathrm{F}) /\left(\mathrm{s}^{2} \mathrm{~m}\right)^{3}\right)$ is described as:

$$
\mathrm{k}=\frac{2 R_{2} \theta^{2} C_{M}}{\operatorname{area}}
$$

$R_{2} \quad$ distributed axoplasm resistance which is much greater than the resistance of external conducting fluid $(\Omega / \mathrm{m})$

$\theta \quad$ propagation velocity $(\mathrm{m} / \mathrm{s})$

area cross-sectional axon area $\left(\mathrm{m}^{2}\right)$

The H-H model can also be represented as an electrical circuit (Figure 12) that gives a good approximation of an axonal potential along the axonal wall. Roy [40] and Lewis [41, 42] both implemented H-H's equations in physical hardware. Both of these models were designed to study neural networks but unfortunately, both of these models also suffered from technology limitations of the time (around 1970). Neither model offered a mechanism with which electrodes could be coupled, nor did they have the correct physiological potential levels. Other physical models exist, such as the cuff electrode specific tester, where the compound AP signal from multiple axons firing in a physiological mode of operation was calculated. This compound calculated waveform was "constructed" to be imposed on a pair of source electrodes [43].

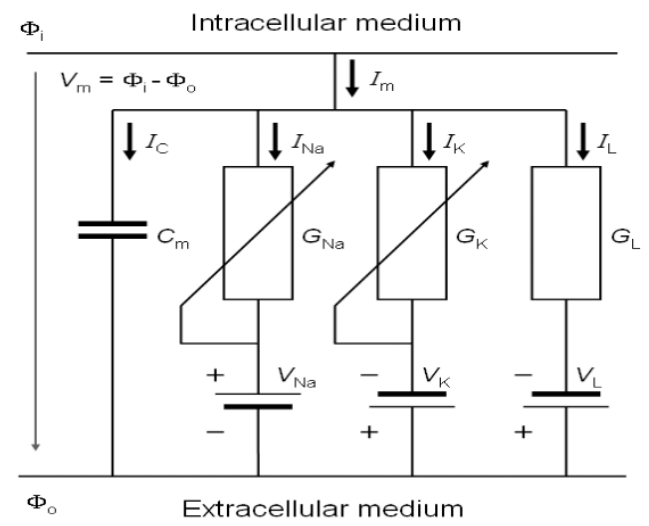

Figure 12 Electrical equivalent circuit based on $H-H$ [4], implementing the function at a node of Ranvier. This model only addresses the fast $\mathrm{Na}^{+}$and $\mathrm{K}^{+}$ion channels that H-H defined. Where: $G_{N a}=\bar{g}_{N a} m^{3} h, G_{K}=\bar{g}_{N a} m^{3} h$, and $G_{L}=$ $\overline{\boldsymbol{g}}_{\boldsymbol{l}}$. Reproduced with permission from Malmivuo and Plonsey [16] 
While the $\mathrm{H}-\mathrm{H}$ model is viable, a more physiological model was developed with further refinements. For example, slow $\mathrm{K}^{+}$and $\mathrm{Na}^{+}$ion channels were now added to the model [44-46]. These slow channels have a slower closure resulting in longer open times. The slow channels mostly affect the refractory period of the AP and membrane after potentials [6].

The electrical implementation of the $\mathrm{H}-\mathrm{H}$ circuit defines the electrical function of the node of Ranvier. To complete the circuit, axoplasmic and exoplasmic path impedances need to be considered. The configuration of one node of Ranvier and the inner and outer impedances from one segment form part of a transmission line. The transmission line circuit would be built from the multiple blocks chained together.

When measuring the AP signal from an axon, the electrode configuration needs to be considered. If one electrode could be placed inside the axon, and the other outside, then the AP measured would look like that in Figure 9. In most cases, this is not possible. Nevertheless, a remotely located reference electrode together with a local signal detecting electrode will produce results that approximate those shown in Figure 9. More commonly, however, a differential electrode configuration is used where the reference and signal detection electrodes are co-located with a small displacement between them. In this case, any static biological signal will result in a $0 \mathrm{~V}$ recording. A signal that presents a voltage gradient, for example a propagating AP, will result in a small difference in voltage between the two electrodes and will result in a non-zero signal. Implicitly the traditional AP wave shape from Figure 9 represents the signal source, but here, it is the "difference" voltages detected by the electrodes at their displacement relative to the AP signal that will be recorded.

\subsubsection{Test Signal Detection}

Reversing the process and using an axonal process as a synthetic trigger detector is also possible. This form of the axonal model is used for assessments of stimulation source thresholds and parameters needed to trigger an AP. One model that can be used in these types of investigations is the "cable model". Implementation of the axonal cable model needs to include active elements and threshold sensing which is more detailed than a simple resistor-capacitor passive model. For example, the internodal voltage gradients can be measured to determine if the trigger threshold is reached. If the threshold requirement is met, then the axon is presumed 
to have been activated and an AP will propagate from the trigger zone outwards along the axon. The cable model structure for this application merges Rushton's work on nerve ratio parameters (such as propagation speed, diameter rations, and myelin/axon ratios, g factor, [47] with $\mathrm{H}-\mathrm{H}$ 's work on the node of Ranvier model [18] and Wesselink's human neuron parameters for tuning of the model [48]. This work has resulted in the developed and implemented of a single cable model by Martens [10]. McIntyre [6] implemented a similar model using a double cable model. The base configuration is similar in both with the added second cable structured used to represent the myelin properties as a resistor and capacitor.

Both neuron models are presented in detail in chapter 7 and PAPER IV. Input to these models consists of a set of potentials sampled along a line. The line is placed in the simulated electric field generated from a source electrode in a volume conductor. The second main parameter which is applied to both models is the input pulse. The pulse is shaped to mimic the pulse generated from an implantable pulse generator (IPG) for DBS. A comparison is made between these two models (PAPER IV) with regards to the resulting activation distance outputs and performance of these two models. The resulting stability and correlation of outputs in response to the same inputs are compared. 


\section{Electrodes}

\subsection{Design and Construction}

Two general groups of electrodes exist -recording electrodes and stimulating electrodes. Both have their place, and both have a unique set of requirements in their designs. Recording electrodes divert a small percentage of the current from the biological source through the external instrumentation. If a large enough percentage of the current were to be diverted through the electrodes, the propagating AP can be quenched, because there would not be enough current to "activate" the following node of Ranvier. The receiving electrodes exhibit a range of properties from completely polarizable, where a capacitive coupling is formed with the tissue, to a completely non-polarizable electrode, where ions and electrons can freely move between electrode and tissue. An example of a non-polarizable electrode is the Silver-Silver Chloride $(\mathrm{Ag}-\mathrm{AgCl})$ electrode. This is a very common configuration with examples shown in Figure 4 a-f. A non-polarizable electrode could be made of stainless steel, or some other conductive substance that has been passivated with an insulator (dielectric) as in developments of non-contact electrodes used for EEG which are electrically insulated from the tissue [49].

Recording electrodes are designed to meet a set of tests defined in the EC-12 standard [50], which is referenced by the U S Food and Drug Administration (FDA) [51] guidance document for ECG surface electrodes. Within the document, there are a set of tests that must be passed before an electrode can be certified for clinical use. Device under test (DUT) parameters are as follows. Paired electrodes must have an AC impedance of less than $3 \mathrm{~K} \Omega$ with a $10 \mathrm{~Hz}$ driving frequency and a source that is current limited to $100 \mu \mathrm{A}$ peak to peak. The DUT must not exceed $100 \mathrm{mV}$ of DC offset voltage when a $10 \mathrm{nA}$ current is applied. Other tests include bias current tolerance, defibrillator overload recovery, and combined offset instability and noise values. Other requisite tests are more related to patient safety, for example, electrode recovery after defibrillation and glue skin contact compatibility. 
Stimulation electrodes also have a defined set of requirements. The most critical is that they must be stable when exposed over the long term to the body's fluids. Secondly, they must be able to freely inject electrons into the surrounding tissue without self-damage. High current surface densities will cause metal ions to become detached from the surface, eventually eroding the electrode, and contaminating the tissue with the metallic molecules. While this is an interesting area of research, it is not covered to this thesis and is only mentioned for completeness. It should be sufficient to know that the material most commonly used in these electrodes is an alloy of platinum-iridium. Platinum is used for its stability and inert properties, and iridium for its electron emittance properties.

\subsection{Application}

Each recording electrode has a specific name based on the measurement target, for example: the electroencephalogram (EEG) is a measure of the bulk neuronal electrical activity of the brain from the skin's surface, the ECG is a measure of the bulk muscular electrical activity produced by the heart, and the electromyogram (EMG) measures the muscular electrical response to stimulation of the associated nerve bundle that connects to the muscle. Other measurement types include electroneurogram (ENG), electrooculogram (EOG), electrocorteogram $(\mathrm{ECoG})$ and electroretinogram (ERG) $[8,52]$. The construction of these recording electrodes is summarised in Table 1.

Stimulation electrodes also exist, such as DBS and pacemaker electrodes. These include leads 3389 and SURESTIM 1 from Medtronic (Medtronic, USA), leads 6148 and 6180 from St Jude (St Jude, USA), and Vercise $^{\mathrm{TM}}$ primary cell system from Boston Scientific (Boston Scientific, USA). SURESTIM 1 and 6148 leads are also designed specifically to steer the field by activating either a set of surface contacts (SURESTIM 1) or one or more segments of a split ring (6148 lead) (Figure 5b). The most recent developments record from the stimulation electrode as well. In the case of the pacemaker, this is already on the market. This specific application monitors the hearts signal, analyzes the signal, stores a "report" and activates the pacing function when needed. 
Table 1. List of medical tests that acquire bioelectric signals from the human body with electrodes. Data abstracted from Webster [52] and Parsson [53]

\begin{tabular}{|c|c|c|c|c|}
\hline $\begin{array}{l}\text { Type of } \\
\text { test }\end{array}$ & $\begin{array}{l}\text { Description of } \\
\text { test signal } \\
\text { source }\end{array}$ & $\begin{array}{l}\text { Typical } \\
\text { Construction }\end{array}$ & $\begin{array}{l}\text { Contact } \\
\text { Dimensions }\end{array}$ & $\begin{array}{l}\text { Expected signal } \\
\text { and noise info }\end{array}$ \\
\hline ECG / EKG & Heart muscle & $\begin{array}{c}\text { Wet gel; } \\
\text { Ag-AgCl; } \\
\text { sticky flat pad }\end{array}$ & $\begin{array}{c}26.5 \times 23.5 \mathrm{~mm} \\
\text { rectangle } \\
\text { contact; } \\
23.5 \times 34 \mathrm{~mm} \\
\text { tab; } 9.5 \mathrm{~mm} \\
\text { diameter circle; } \\
8 \text { to } 10 \mathrm{~mm} \\
\text { diameter circular }\end{array}$ & $\begin{array}{l}1 \mathrm{e}-3 \text { to } 5 \mathrm{e}-3(\mathrm{~V}) \\
1 \text { to } 100(\mathrm{~Hz})\end{array}$ \\
\hline ECoG & $\begin{array}{l}\text { Brain's bulk } \\
\text { activity at the } \\
\text { surface of the } \\
\text { brain }\end{array}$ & $\begin{array}{c}\text { Wet gel; } \\
\text { Ag-AgCl; } \\
\text { sticky flat pad }\end{array}$ & --- & $\begin{array}{l}1 \mathrm{e}-3 \text { to } 2 \mathrm{e}-3(\mathrm{~V}) \\
10 \text { to } 50(\mathrm{~Hz})\end{array}$ \\
\hline EEG & $\begin{array}{l}\text { Brain's bulk } \\
\text { nerve activity } \\
\text { transcranial }\end{array}$ & $\begin{array}{l}\text { Wet gel; } \\
\text { Ag-AgCl; } \\
\text { sticky flat pad, } \\
\text { dry non-- } \\
\text { contact } \\
\text { electrode }\end{array}$ & --- & $\begin{array}{c}1 \mathrm{e}-6 \text { to } 300 \mathrm{e}-6(\mathrm{~V}) \\
0.1 \text { to } 100(\mathrm{~Hz})\end{array}$ \\
\hline EMG & muscle & $\begin{array}{c}\text { Wet; } \\
\text { Ag-AgCl; } \\
\text { suction cup }\end{array}$ & $\begin{array}{c}20 \mathrm{~mm} \\
\text { diameter circle, } \\
24 \mathrm{~mm} \text { face } \times \\
9.5 \mathrm{~mm} \text { deep; cut } \\
\text { sphere } \\
\end{array}$ & $\begin{array}{l}3 \mathrm{e}-6 \text { to } 2 \mathrm{e}-3(\mathrm{~V}) \\
1 \text { to } 10 \mathrm{e} 3(\mathrm{~Hz})\end{array}$ \\
\hline ENG & $\begin{array}{l}\text { Nerve activity } \\
\text { along nerve } \\
\text { track at two } \\
\text { points, with } \\
\text { known } \\
\text { separation. To } \\
\text { assess } \\
\text { propagation } \\
\text { velocity. }\end{array}$ & $\begin{array}{c}\text { Wet; } \\
\text { Ag-AgCl; } \\
\text { suction cup, } \\
\text { needle } \\
\text { electrode }\end{array}$ & --- & $\begin{array}{l}3 \mathrm{e}-6 \text { to } 2 \mathrm{e}-3(\mathrm{~V}) \\
1 \text { to } 10 \mathrm{e} 3(\mathrm{~Hz})\end{array}$ \\
\hline EOG & $\begin{array}{l}\text { Ocular orb small } \\
\text { muscle activity } \\
\text { To assess the } \\
\text { direction the eye } \\
\text { is pointing. }\end{array}$ & $\begin{array}{c}\text { Wet gel; } \\
\text { Ag-AgCl; } \\
\text { Sticky flat pad }\end{array}$ & $\begin{array}{c}8 \text { to } 10 \mathrm{~mm} \\
\text { diameter circular }\end{array}$ & --- \\
\hline ERG & $\begin{array}{l}\text { Electrical } \\
\text { activity of the } \\
\text { retina in the eye }\end{array}$ & $\begin{array}{c}\text { Wet gel; } \\
\text { Ag-AgCl; } \\
\text { Sticky flat pad }\end{array}$ & $\begin{array}{c}8 \text { to } 10 \mathrm{~mm} \\
\text { diameter circular }\end{array}$ & --- \\
\hline
\end{tabular}


For every electrode, there appears to be a need for specialized test platform. To compare one electrode to another in terms of function should not be dictated by the electrode's own structure. To test and verify an electrode, it should be possible to use a physical generalized action potential generator. Modeling in software and simulations are a must once a design is conceived, but physical testing should also be a requirement.

\subsection{The Ideal Model for Electrode Testing}

Testing of an electrode in its perfect environment implies testing within an idealised environment of target tissue and organ under optimal conditions. For example, a surface recording electrode (Figure $13 \mathrm{a}, \mathrm{b}$ ) must be able to detect nerve electrical activity through the mass of tissue that separates the signal source from the electrode interface. In many cases, that is not possible. Recording a signal from a human arm would require exact placement of the center of the electrode on the same point on the arm each time an electrode is applied. The biological reality is that even if the same point on the arm, i.e. the source, could be targeted, the nerve bundles involved will not generate the exact same signal every time.

a

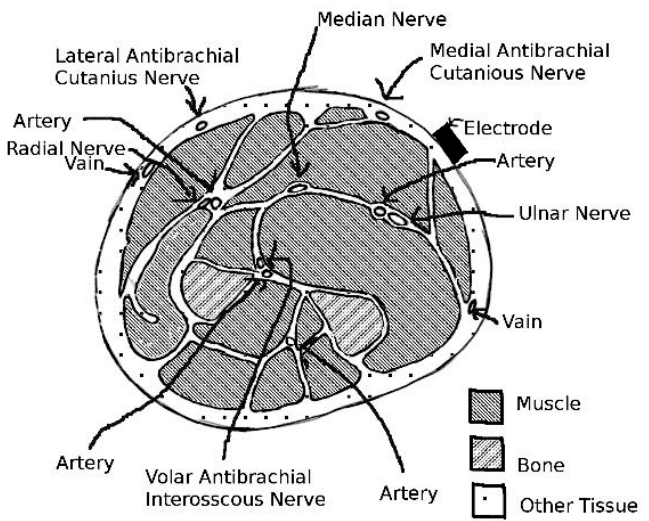

b

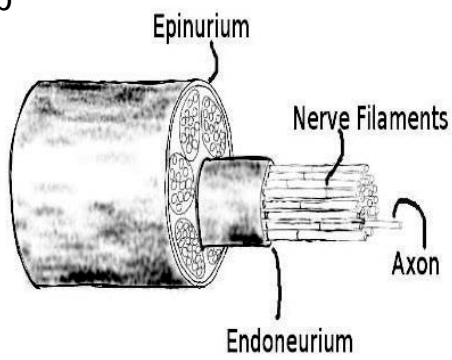

Figure 13 a) Diagram showing the position of structures in a sectional view of the central part of the forearm with nerve positions indicated. b) Diagram representing a typical peripheral nerve bundle found in the human body with its component parts described down to a single axon. Permission granted by Latorre [8]. 
Simplified models can be developed to meet specific test cases, but a good understanding of the physiological details is needed. For example, the electrophysiological interactions of the tissues in Figure 13a may be modelled with a medium or implied electrical model (Figure 14 a, b). Roth's work [54] entails a detailed assessment of tissues and their electrical equivalent circuits. The skin has its own contributing factors as described in Figure 15.

a

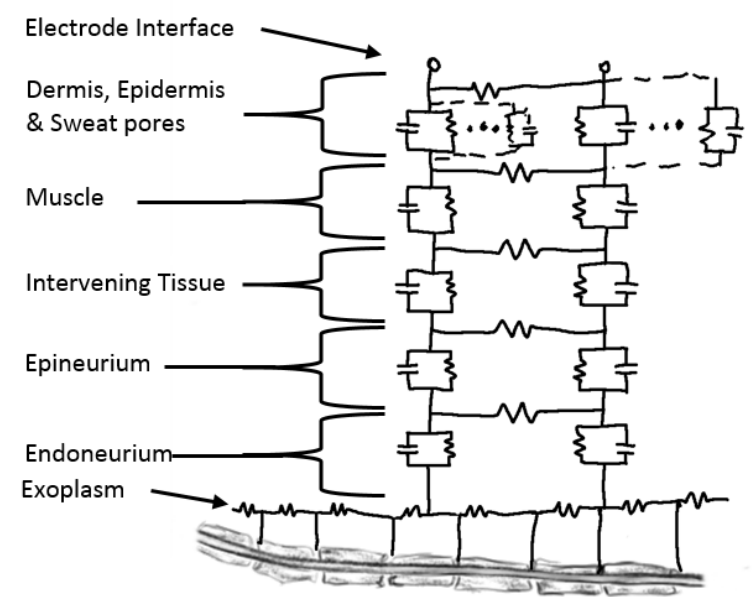

b

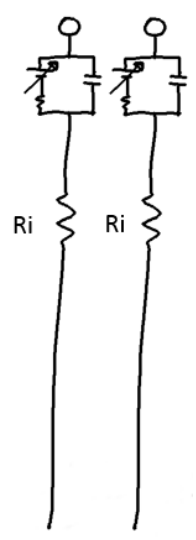

Figure 14. (a) A simplified electrical equivalent of the path that an AP current must pass to get from the ulnar nerve to the electrode face based on Figure 13 a and b. (b) This electrical model is typically used to describe the skin and subdermal properties. $\mathrm{Ri}$ is the intervening bulk tissue resistance ignoring capacitance. The electrode interface takes into account the epidermis capacitance, the epidermis resistance, and the Nernst potential at the interface.

In vivo biological sources are expected to be the best models available to test an electrode, but this is not specifically true as tissues are inherent heterogeneous. In vitro, while specific environmental constraints can be maintained, inherent tissue heterogeneity and the sensitivity of nerves to tissue culture conditions makes it difficult to maintain stable and repeatable AP generation parameters. This makes biological signal 
sources non-ideal for developing of a testing or calibrating system, or for characterizing electrode performance and parameters acquisition.

A good example of a biological source used for testing can be found with the cuff electrode, which is a very specialized implementation of a biopotential electrode. The cuff electrode wraps around a nerve bundle confining the ionic flow and electrically isolating the signal from the bulk of the tissue in a short segment of the bundle. The design and implementation of this electrode requires the restriction of the ionic flow to the space between the nerve bundle and the "cuff", thereby effectively amplifying the electrical signal that can be detected at the electrodes. It should be noted that this electrode is placed around the nerve bundle as an implanted device and is therefore invasive.

An example of a biological source used for electrode testing is the "earthworm" [55]. For the reasons noted in PAPER I, biological sources should be limited to qualitative testing only. Electromechanical models that emulate an AP also exist. One model constructs a complex amplitude controlled signal that is applied to a small set of electrodes that in turn emulate a propagating multiaxonal AP, while the other uses a single source point that is translated by moving throughout the fixed position cuff ring $[43,56]$. Other sources that could be used are once again in vitro cell cultures but their limitations must be understood and culture conditions that must be maintained throughout the complete experimental investigation.

While surface ECG electrodes have a standard to which they must adhere [57] that is based on the Association for the Advancement of Medical Instrumentation standard EC12:2000/R2010 [50], other biopotential interfaces are assessed on a one-on-one specification for efficacy based on specific patient clinical trials.

The "golden standard" for electrode testing does not exist. The closest approximation to date is an averaged model of the most likely environment possible for electrode testing. However, there is still the possibility to use one platform against which a wide range of electrodes can be tested. This single test environment should allow for a better understanding of how the electrode design and configuration interact with the "anatomical" environment to which the electrode is applied, as well as highlight the differences in design and how they are tailored to specific applications. "A dedicated test and calibration system will have no value 
if the interest is only in pulse event information, but once details such as shape, amplitude, or timing are investigated, then a calibrated electrode and system become important" (PAPER I).

\subsection{The Tissue-Electrode Interface}

The signal that is recorded and transmitted as the final displayed data by electrodes is generally not the original signal at the source. This is because confounding artifacts are introduced by the process of measuring. Artifacts can originate from surrounding tissues of the subject, e.g. bone (skull in EEG), fat (signal attenuation) or muscular activity (heart beat or breathing, electrical summation of signals in ECG). Artifacts can also originate from the detection system. These include the type of electrode used (DC offset, stability, electrode gain or attenuation, frequency bandwidth limitations, signal integration), or amplifiers and displays (non-linear gain, quantization noise). As an example, the gap between the source of the nerve AP up to, but not including, the skin where the electrode is attached, is typically modeled as a single resistive element (Figure 14a). This simplification ignores the intervening connective tissue, fat, muscle, blood vessels, etc. that would otherwise necessitate a complex circuit (Figure 14b). However, even the complex circuit is already a simplification of the true $3 \mathrm{D}$ structure that includes many coupled parallel-series networks of resistance and capacitance.

Surface electrodes have to consider the interface of the skin in their design. The skin is dry and relatively non-conductive and behaves more like an electrical capacitor than resistor. Figure 15 shows the anatomical features of the skin together with the expected dominant electrical parameter for each of its layers that confound the acquisition of the AP signal. When a biopotential is measure transcutaneously, a complex equivalent electrical circuit that includes many parallel-series connected circuit elements of resistors and capacitors should be applied to best represent the intervening tissue Figure $14 \mathrm{~b}$. A more complex skin model is presented by Gruetzmann [58] which includes resistance, capacitance and interface potentials caused by ion concentration differences (Nernst voltages) in the tissue. 
The tissues and structures shown in Figure 13 and Figure 15 are all contributing factors to signal distortion. The final signal at the lead wires after the electrode interface can be distinctly different from that of the source. Biopotential electrodes are rarely in direct contact with the nerves or muscles that they are supposed to couple with, although there are a few notable exceptions. Transdermally placed needle electrodes are used for muscle and nerve assessments. When possible, the needle is placed inside the nerve's surrounding perineurium sheaths, but these electrodes are still not in direct contact with the axon of interest, just very close.

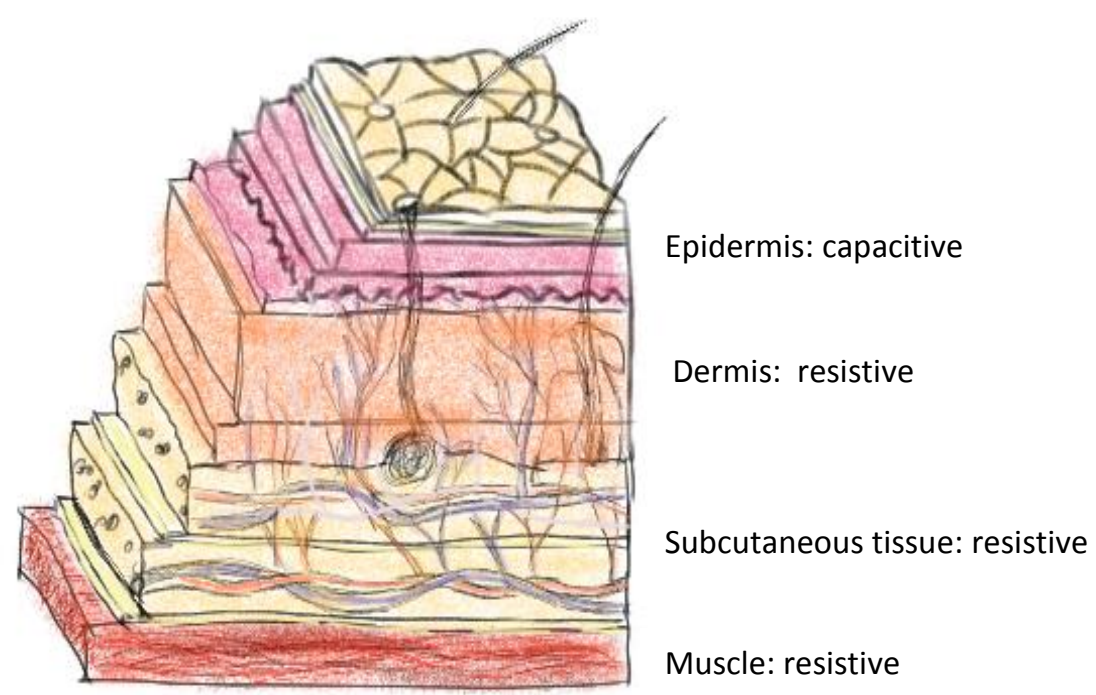

Figure 15. Detail of full thickness human skin down to the muscle layer. Each layer has an orientation of least resistance, which does not always align with axis of detection (transverse through the skin). All tissues present a complex impedance composed of resistive, capacitive and inductive parameters. The dominant characteristic of each layer is listed with the text naming the layer. Reproduced with permission from Latorre [8]

For DBS, the immediate brain region around the electrode is the tissue of interest. The electrode is a stimulating one and is not typically used for recording of the electrical activity of the surrounding tissue. What is of importance is the coupling efficiency, the electrode surface 
resilience to its environment (tissue contact and electrical currents) and the volume of tissue that is activated. The electrode material and construction are out of the scope of this work, so only the method by which the electrode couples to tissue is considered.

It has been documented that the distance from the electrode to where the tissue is activated, i.e. an AP is triggered along an axonal process, is limited to a few $\mathrm{mm}[10,59]$. It is therefore hypothesized that the efficacy of DBS stimulation is due to triggering of APs, although quenching of activity that is passing through the influenced tissue is also still a possibility. The likely reality is a combination of both effects [60] as well as coupling between brain regions.

The stimulation exceptions are more common, such as the DBS lead itself or the cardiac pace maker lead that is in direct contact with the muscle tissue of the heart. Other examples are microelectrode recording (MER) electrodes used as intraoperative measurement tools in relation to DBS lead implantation.

\subsection{The Need for a Common Electrode Test Platform}

At present, new electrode designs generally result in an accompanying specialised test platform of their own. This has resulted in a plethora of test platforms that make it extremely difficult if not impossible to determine equivalence of clinical data acquired using one electrode to another. One example of this phenomena can be found with cuff electrodes. Rieger [43], Andreasson [56], and Yoshida [55] have all developed their own test platforms. Rieger et al. created a test model that implemented a limited number of electrodes mimicking an axonal segment. The impulse presented to the electrodes was computed to emulate the AP from multiple nerve fibrils firing concurrently. Andreasson et al. implemented a mechanical device that emulated the physical displacement of a potential source through the volume enclosed by the cuff electrode, and Yoshida et al. used the earthworm as a biological source for the neuron. Surface biopotential electrodes is a second area that also shows innovation and limitations in testing, where some researchers tested on human subjects $[58,61]$ while others tested using a combination of biological tissues and specialized hardware [62].

New electrodes are being developed for both traditional applications and innovative diagnostics (e.g. EEG, ECG, EMG), and 
stimulation therapies, e.g., for brain computer interface (BCI), DBS, and nerve signal detection. The traditional wet/gel contact electrode is still in use, but increasingly, glues and electrolytic gels are taking over. Dry contact electrodes are considered an extension of the wet electrodes but use a different mechanism for electrical charge coupling to human tissue, where they do not suffer electrolyte dry out. Most new innovative electrodes are dependent on induced charge transfer instead of direct electrical current coupling, with some having traits of both, e.g. textile electrodes [62]. However, even these must still be applicable to, and work in tandem with existing systems in a medical environment.

To extract the transfer function of the electrode under optimal conditions, a static swept frequency test can be performed. The conditions under which testing is performed limits the interpretation of the transfer function, as a comprehensive picture is not available. A dynamic test platform, where the source signal is translated through physical distance could be advantageous. A more complete understanding of electrode coupling parameters under dynamic conditions that mimic the native biological conditions could also provide more accurate results.

The most important prerequisites of a test platform are repeatability and stability of the emulated AP. Previous test platforms have focused on a single electrode type, and testing for that specific design only $[43,56]$. A broad-based test platform that can be used for a range of electrodes is needed to allow a better understanding of how each different electrode reports the AP signal, to be able to make comparisons. Ex vivo nerve cultures at first glance appear to be an optimal test platform since they are closest to in vivo testing without being in vivo. However, the innate heterogeneity of native tissues mentioned previously and the unexpected responses to tissue culture conditions make the signal qualitative. These limitations have been part of the inspiration for the work in this thesis. Better understand of the details of the interface should result in a better understanding of the resulting acquired signal. 


\section{Aim}

The general aim of this thesis was to facilitate the development and characterization of biopotential electrodes. The desire to test and compare electrodes in an environment that best mimics the physiology around the application was approached and resulted in the development of a fully synthetic, physical axon model - the Paxon.

The aim was broken down in this thesis to:

- Design, construction, and implementation of a platform that emulates a physical axon to test medical electrodes.

- Evaluation of the Paxon's performance parameters i.e. repeatability, stability, drift, programmability.

- Validation of the Paxon's efficacy by testing ECG electrode parameters.

- Application of a single cable neuron simulation model for investigation of activation distance in DBS studies.

- Characterization of a pair of neuron models, single and double cable models, and their feasibility and complexity based on a range of axon diameters, sensitivity to triggering source and computational time. 


\section{The Paxon Development}

The Paxon was developed based on a myelinated peripheral neuron of $20 \mu \mathrm{m}$ diameter. Such a neuron would typically have an axonal process with an average node spacing of $2 \mathrm{~mm}$ and an AP propagation velocity of around $120 \mathrm{~m} / \mathrm{s}[15,47]$. The constraints of such an axon were mimicked in the physical construction of the well.

The Paxon was developed in a series of steps. The first stable model is presented in PAPER I. The main purpose of the Paxon generator was to produce an electric field in normal saline solution in a manner that is similar to a biological AP with respect to amplitude and duration, but not wave shape. The details of the development of an AP generator are found in PAPER I.

The basic components of the Paxon (Figure 16) are the well, located to the far right, which is where the wire nodes of Ranvier, tissue mimic and electrodes connect. The node buffer, and control circuit located bottom, centrally next to the well, the optically isolated external control located, the two power supplies, the rotation end-effector located to the far left, and finally the data acquisition and control box with bias circuits located center top (Figure 16). To aid in repeatable positioning for measurements, an XYZ micrometer arm was used to locate the electrodes in the well. A server motor was added to the system for electrode rotation tests. This complete system was then placed inside a Faraday cage to reduce external electromagnetic interference. The Paxon was controlled and data was collected using a LabVIEW ${ }^{\circledR}$ program. Data analysis was performed after data collection using OpenOfficeCalc ${ }^{\circledR}$ (The Apache Software Foundation, California, USA) software. 


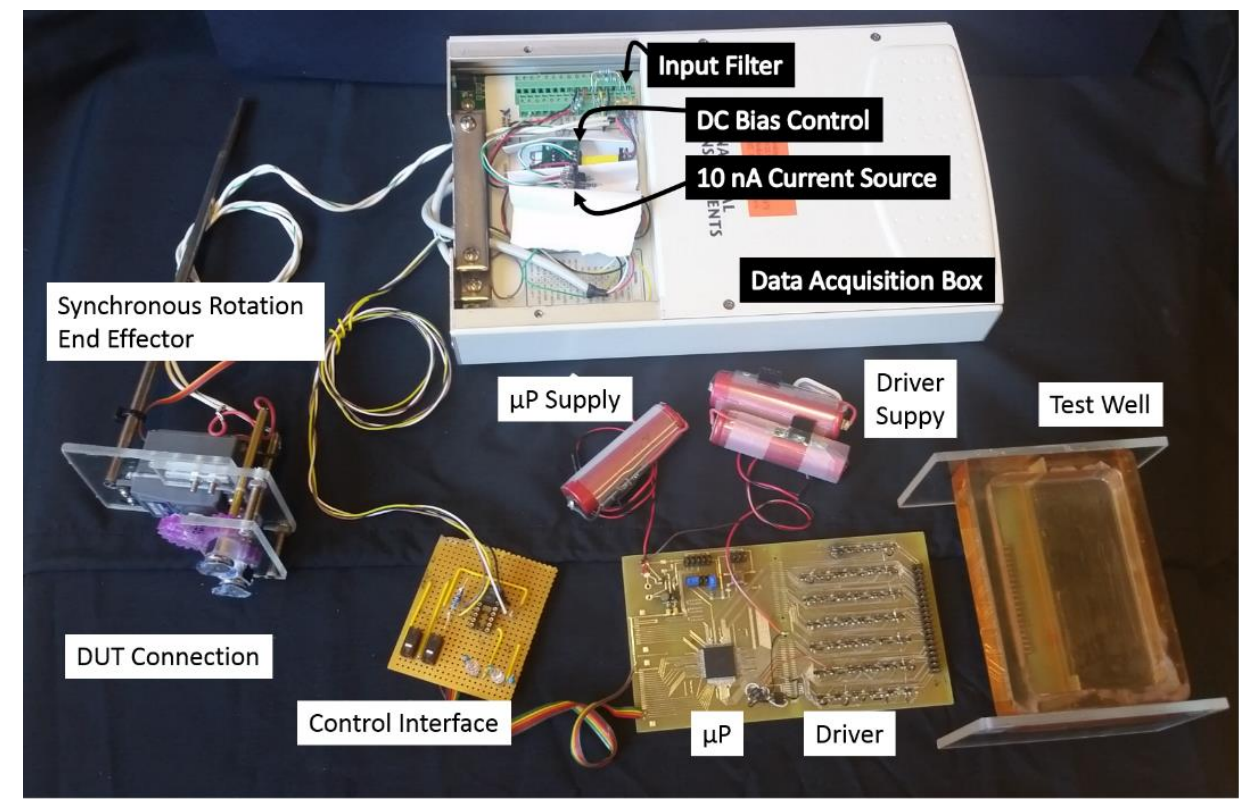

Figure 16. Paxon test platform. The model comprises gold wire (20 $\mathrm{\mu m}$ diameter) cast into a block of Epoxy resin, with a driver circuit that was built on MOSFET switches with the drive voltage and gate control directed by a microcontroller. The external controls are dielectrically isolated. The entire test platform is powered by battery.

\subsection{Test Well Construction}

The first well was built using circular profile standard copper $(\mathrm{Cu})$ wire of $44 \mathrm{AWG}$ or $20 \mu \mathrm{m}$ in diameter. The $\mathrm{Cu}$ wire was attached to a frame that held the wires at $2 \mathrm{~mm}$ spacing. A total of 32 wires were used (Figure 17). The wire was fused between two sheets of poly(methyl methacrylate) (PMMA) using dichloromethane solvent. Many sheets were layered together to form a composite block. The composite block was machined flat on top, then a well was machined into the block (Figure 18). The second model was constructed using circular profile $20 \mu \mathrm{m}$ gold (Au) wire (99.99\% Au, SPM, Armonk NY, USA). 


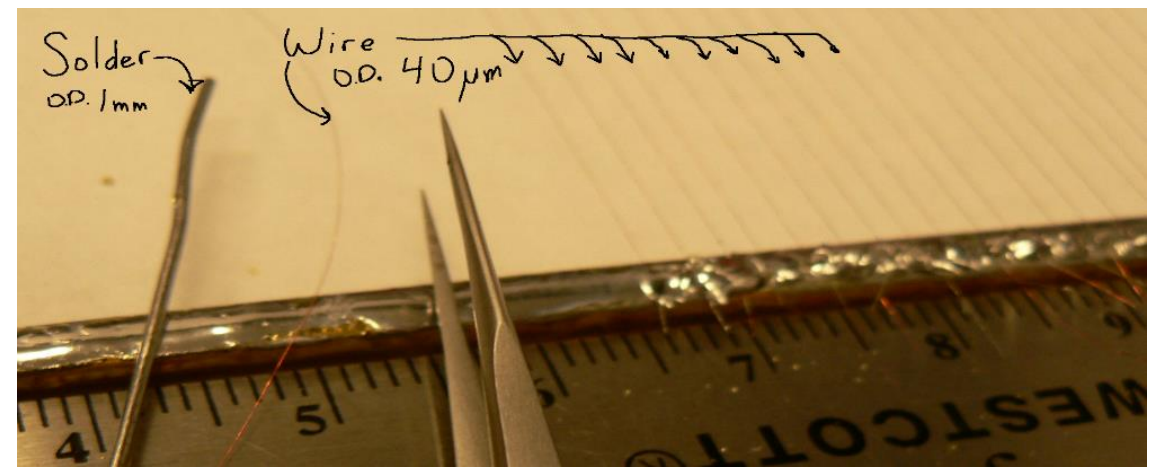

Figure 17. Partially assembled frame with 40 AWG copper. The frame is made of $3 \mathrm{~mm}$ brass $U$ channel that is soldered together. The wires were placed and soldered to the frame with the aid of tweezers before lamination in PMMA.

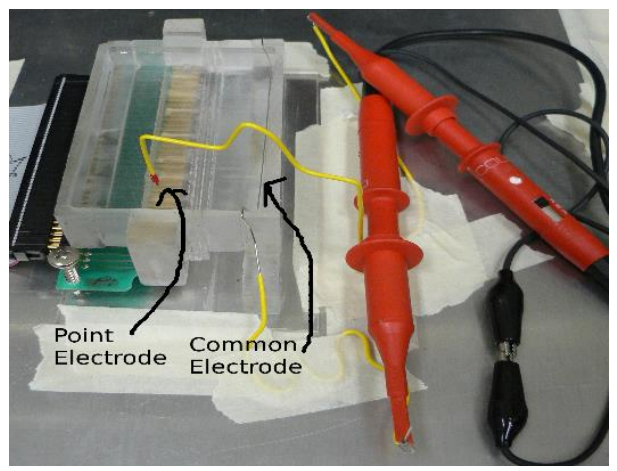

Figure 18. Assembled laminate well with test electrodes in place. Metal base is part of the Faraday shield. Oscilloscope probes are used to couple the DUT electrodes (EL) to an oscilloscope differential amplifier as the front end of the data acquisition system.

Success with the $20 \mu \mathrm{m}$ Au wire was found using a different construction technique. A circuit board was designed to connect the $\mathrm{Au}$ wire to a standard 40 pin IDC connector. The circuit board design incorporated traces spaced $2 \mathrm{~mm}$ apart along the length of the board's surface. A rectangular cut-out in the board was made transecting the traces. This open space was bridged by the Au wire using the wirebonding technique developed in the integrated circuit industry (Figure 19 a). 

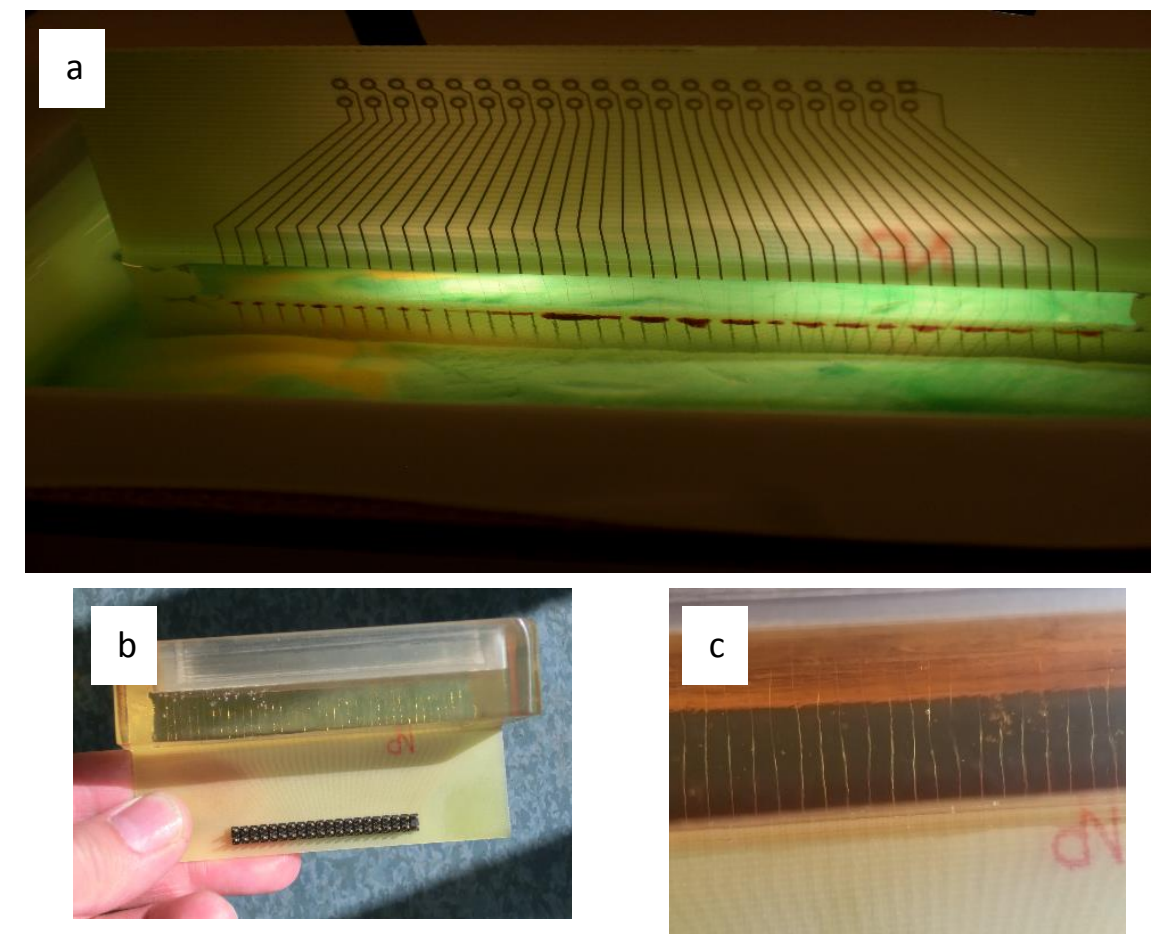

Figure 19. a) Prepared wire bonded circuit board being encapsulated. b) Completed machined assembly seen from the side. Gold wires can be seen passing from the bottom connector side to the machined well at top of image.

c) Close up of embedded gold wires in well base from sub-image b.

The cut-out of the circuit board was placed in a mould with the IDC connector located above and outside of the mould volume. The mould form was then filled with epoxy (EPOTek 301, Epoxy Technology Inc., USA) and left to cure. Once demoulded, the assembly was oriented with the IDC connector down, and the top surface was machined flat. A well $56 \mathrm{~mm}$ wide, $92 \mathrm{~mm}$ long, and $11 \mathrm{~mm}$ deep was then milled into the epoxy forming the test chamber. The Au wires enter from the bottom of the well and are parallel to the long axis e.g. 40 elements spaced $2 \mathrm{~mm}$ apart (Figure $19 \mathrm{~b}$ ). A close-up of the encased $20 \mu \mathrm{m}$ gold wire is shown in Figure 19c. The well dimensions and possible extensions are listed in Table 2. 
Table 2. Paxon well dimensions and configuration properties

\begin{tabular}{|l|l|}
\hline Parameter & Data \\
\hline Well dimensions & $11 \mathrm{~mm} \times 56 \mathrm{~mm} \times 92 \mathrm{~mm}$. \\
\hline Center of well structure & Over node 20 \\
\hline Position of node axis & $\begin{array}{l}\text { Bisects well centrally, } 28 \mathrm{~mm} \text { from } \\
\text { long side }\end{array}$ \\
\hline Lateral Distance to wall & $28 \mathrm{~mm}$. \\
\hline Axial Distance to wall & $46 \mathrm{~mm}$. \\
\hline Spacing of nodes & $2 \mathrm{~mm}$. \\
\hline Length of axon segment mimic & $80 \mathrm{~mm}$. \\
\hline Depth of well & $11 \mathrm{~mm}$, can be extended. \\
\hline Electrode position above well bottom & 0 to 11 mm. \\
\hline Lateral and axial dimension & Can be extended with new design. \\
\hline Number of nodes in Paxon well & $\begin{array}{l}40 . \text { With current controller can be } \\
\text { extended to } 64 \text { nodes. }\end{array}$ \\
\hline Number of active nodes in sequence & $\begin{array}{l}0 \text { to } 16 \text { in } 1 \text { node steps, with a change } \\
\text { of programming can be increased to } \\
\text { more than } 40 \text { in } 1 \text { node steps }\end{array}$ \\
\hline Timing between node updates & $12 \mu$ to more than $1 \mathrm{~s}$, in $1 \mu \mathrm{s}$ steps \\
\hline Node Source Amplitude & $\begin{array}{l}0 \text { to } 2.8 \mathrm{~V} \text { in } 0.7 \mathrm{mV} \text { steps, with } \\
\text { redesign can be changed }\end{array}$ \\
\hline Well Volume & $56.7 \mathrm{ml}$ \\
\hline
\end{tabular}

\subsection{Tissue Mimic}

A normal saline solution $(\mathrm{NaCl})$ was used in the well as the tissue mimic. For other models, this is standard practice, as the bulk conductivity properties are similar to those of tissue with regards to electrode testing $[43,56]$.

The Au wires at the bottom of the well were submerged in the saline solution. The DUT electrodes were placed in contact with the saline solution completing the electrical connection between the electrodes and the axon mimic (Figure 20). 


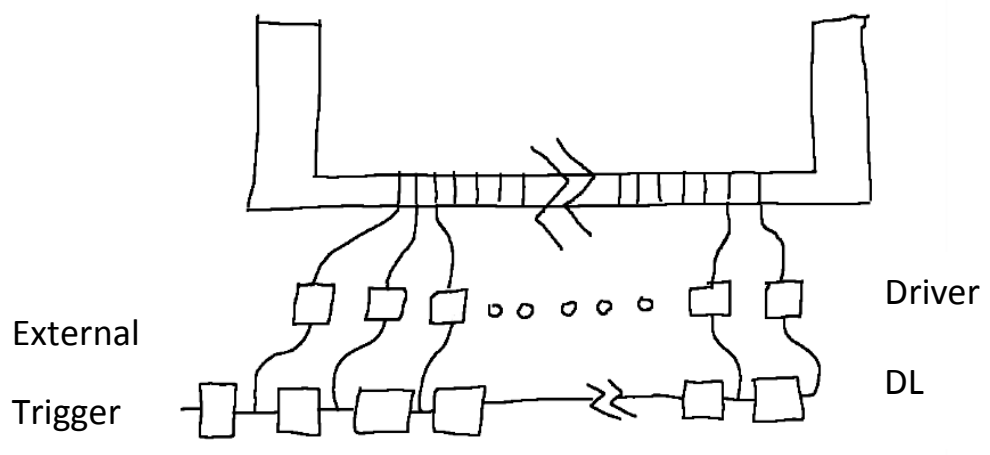

Figure 20. Schematic representation of the Paxon well delay elements (DL) and node driver (Driver). Wire nodes of Ranvier enter the flooded chamber from the bottom of the well.

\subsection{Control Electronics}

The physiological structures involved in the generation and propagation of an AP are mostly located at the nodes of Ranvier. Focusing on the complete function of the ion channels at the node, the waveshape appears to increase smoothly from a resting value through the maxima then reducing to a minima and finally returning to the resting potential. For external measurements, this would represent a transition from $0 \mathrm{~V}$ to $+110 \mathrm{mV}$ to $-20 \mathrm{mV}$ with a final return to $0 \mathrm{~V}$. However, when only a single ion channel is considered, the flow of current through that channel is digital in nature, open or closed. It is the cumulative effect of all ion channels and their probability of being opened, the activating function, $m, n$, and $h$ of the ion channels that result in the smooth potential changes that are measured. The Paxon's node function was based on the behaviour of a single ion channel and therefor was designed to be on or off only.

A circuit that would linearly shift a "pulse" along a set of outputs was designed. The output from the first element in the shift chain was connected to the input of the second element. The output from the second element connected to the third, and so on until the last element in the chain. The digital logic integrated circuit (IC) logic family was the complementary metal oxide semiconductor (CMOS). The CMOS logic 
family requires a supply voltage between 3 and $18 \mathrm{~V}$. The other alternative was the transistor-transistor logic (TTL) family which is designed for operation at the fixed voltage of $5 \mathrm{~V}$. The specific logic function used was the dual Schmitt triggered [63] input quad CMOS NAND gate, CD4093 [64].

The NAND gate was used in a mixed signal design. One of the two inputs to the NAND gate was tied to logic high. In this configuration, the NAND gate functions like a Schmitt triggered inverter with one input and one output used for connectivity. The circuit implements a digital delay chain comprised of one "inverter" one resistor and one capacitor Figure 21.

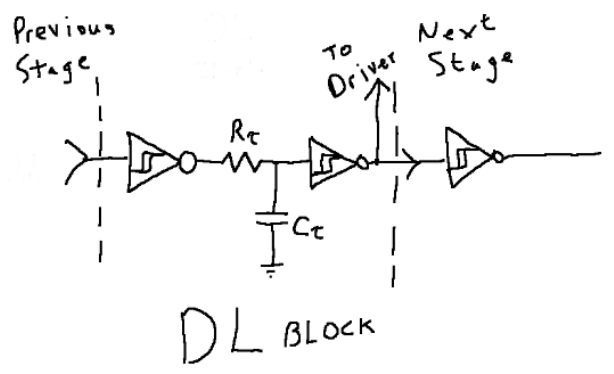

Figure 21. Mixed signal circuit used as the node to node hardware implementation delay element. The delay relies on the equation for charging a capacitor with a voltage (somewhat current limited) and the selectivity of the Schmitt trigger input circuit that cleans up the edge. $\tau=\mathbf{R}_{\tau} * \mathbf{C}_{\tau}$, where $R_{\tau} 75 \mathrm{~K} \Omega$ and $C_{\tau}=1 \mathrm{nF}$.

The Schmitt trigger input was used because of the hysteresis intrinsic in the gate design. Hysteresis works by applying a percentage of the output as positive feedback. For the inverting logic used, the output changes state e.g. low to high, after the input voltage has transitioned from high to low and crossed the lower hysteresis threshold. The hysteresis input-output relationship is plotted in Figure 22, where the output, $\mathrm{y}$ axis, is plotted against the input, $\mathrm{x}$ axis. 


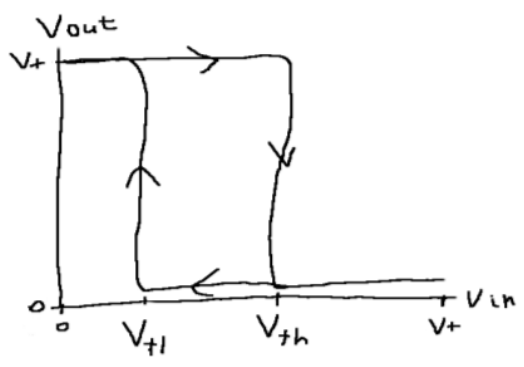

Figure 22. Hysteresis curve plotted as output referenced to input for an inverting gate function.

The delay at each element on the chain was calculate to correspond to the expected mean delay between nodes of Ranvier $\left(\tau_{n}=\right.$ $16.6 \mu \mathrm{s})($ Eq. 5) for a $20 \mu \mathrm{m}$ diameter axon. The propagation velocity and internodal distance was taken from data presented by Rushton [47]. For the delay block (DL) the values for $R_{\tau}$ and $C_{\tau}$ were calculated to be 75 $\mathrm{k} \Omega$, and $1 \mathrm{nF}$ respectively resulting in a delay of approximately $17 \mu \mathrm{s}$ with a $5 \mathrm{~V}$ supply to the integrated circuit.

$$
\tau_{n}=\frac{2(\mathrm{~mm})}{120(\mathrm{~m} / \mathrm{s})}=16.6 \mu \mathrm{s}
$$

An input pulse, or AP trigger, is buffered, then sent to the first delay element. The slow integration of charge on the capacitor reaches the threshold, rising or falling, and the output of the inverter changes state. In this sense, the output of the inverter is a regenerated pulse of the input. The output from one delay element drives the next delay element in the chain until all elements have propagated the pulse. As the signal passes through each delay element, there is a $180^{\circ}$ phase rotation, which would invert every second node. This phase rotation was corrected in the node of Ranvier buffer stage in Figure 23 by alternating between one and two inverter stages between the delay element and the resistor divider. 
The output of the driver was designed as a simple low resistance voltage divider Figure 23 where the wire node impedance was calculated to be less than $20 \mathrm{ohms}$ and capable of sourcing a voltage of 0 and 130 $\mathrm{mV}$ with an input of 0 and $6 \mathrm{~V}$ respectively. The pulse present on the wire node was the same pulse as on the chain input but phase shifted in time. The net effect of the analog delay line was to have the input pulse propagate along the wire nodes to the end of the chain.

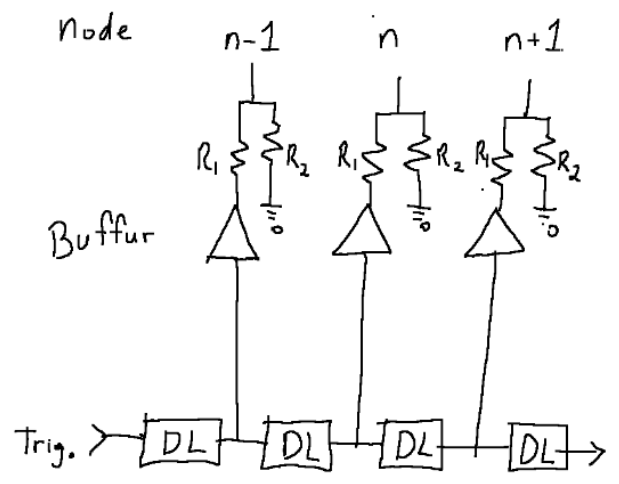

Figure 23. The fixed speed Schmitt delay line (DL) blocks implemented in Figure 21 in the first model, along with the node driver circuit and voltage divider, where $R_{1}=20 \Omega$, and $R_{2}=1 \mathrm{~K} \Omega$.

The final working electronic controller was based on a microcontroller $(\mu \mathrm{P})$. The $\mu \mathrm{P}$ chosen was the ATxmega64A1CPU (Atmel Corp., USA). This $\mu \mathrm{P}$ has sufficient input/output pins (I/O) to assign one output to each node for a total of 40 nodes, as well as analog output control for setting the output analog drive, and I/O for synchronization. The $\mu \mathrm{P}$ core idles at a frequency of $1 \mathrm{MHz}$ to reduce power consumption until activity on the trigger input is detected, then the internal high frequency synthesized clock (32 MHz) is enabled and used to clock the core.

The $\mu \mathrm{P}$ program was written in $\mathrm{C}$ (Atmel Studio 7.0, Atmel, USA). The software code manipulating the $40 \mathrm{I} / \mathrm{O}$ bits was a structure configured as a single block of 40 bits. The I/O buffer registers were updated sequentially in 16 bit blocks. Computationally the data was 16 bits numbers internally manipulated as two 32 bit numbers, and the data 
outputs were updated as a low block of 32 bits and a high block of 8 bits, where the remainder of the 32 bit data was ignored. When the core is clocked at $32 \mathrm{MHz}$, there are approximately 530 clock cycles between node updates, leaving sufficient time for register updates and needed calculations.

The output buffer/driver was also redesigned. An analog voltageoutput pin of the $\mu \mathrm{P}$ was buffered and used as the voltage reference source for all output drivers. This in turn connected to a $1.2 \mathrm{k} \Omega$ resistor which connected to each wire "node". Each individual node was actively turned off by a shunting MOSFET which was controlled by one of the 40 output lines (Figure 23). The $\mu \mathrm{P}$ and output buffers to the nodes were powered by individual isolated batteries (Figure 24).

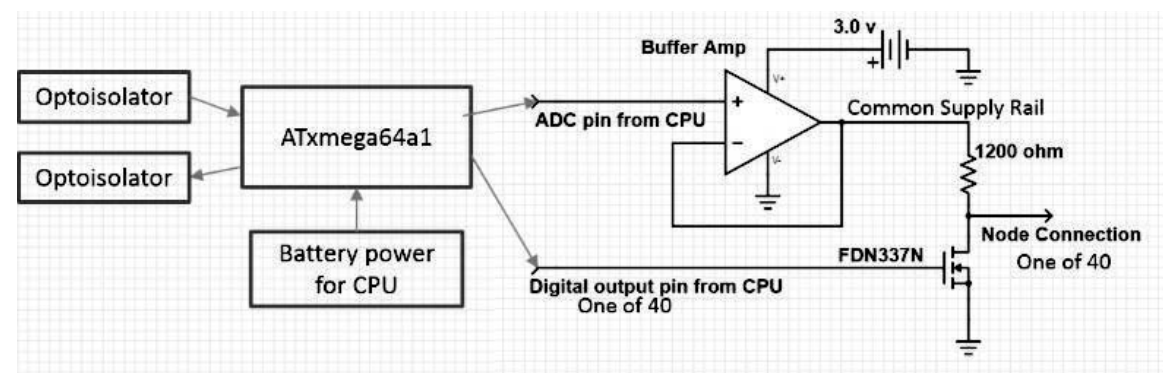

Figure 24. Block diagram of electronics and detailed driver circuit for the node of Ranvier. Reproduced with permission from Latorre [8].

\subsection{Data Capture and Processing}

The first tests were performed using a Hewlett Packard Oscilloscope with a differential amplifier input module as the first stage amplifier. The Y-axis data was collected from the output on the back of the oscilloscope and captured with a National Instruments data acquisition system (NI PXI-1042 with NI PXI-6221 DAQ) for direct analog recording. The tests were performed with a small $\mathrm{Ag}-\mathrm{AgCl}$ wire electrode that was manufactured from a $4 \mathrm{~cm}$ length of $32 \mathrm{AWG}(0.2019$ $\mathrm{mm}$ diameter) Teflon ${ }^{\circledR}$ sheathed silver (Ag) plated $\mathrm{Cu}$ wire that was treated to form the $\mathrm{Ag}-\mathrm{AgCl}$ surface. This prepared $\mathrm{Ag}-\mathrm{AgCl}$ test electrode was coiled before preparation and had a working surface area 
of $2.5 \mathrm{~mm}^{2}$ (Figure 25). A traditional surface $\mathrm{Ag}$ - $\mathrm{AgCl}$ electrode with an $8 \mathrm{~mm}$ diameter contact has an active surface of approximately $50 \mathrm{~mm}^{2}$.

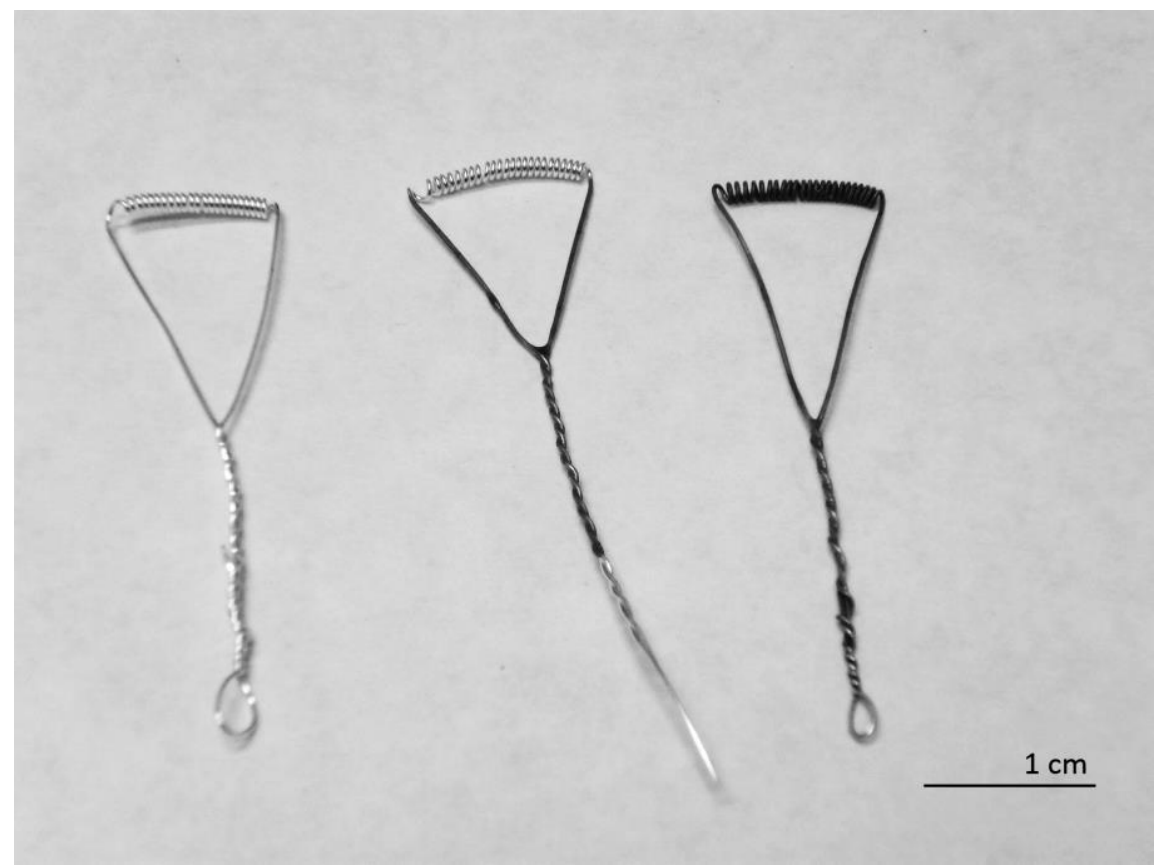

Figure 25. Process steps from left to right of the 32 AWG Ag plated Cu wire, shaped, insulated and finally with the electrolytic formed $\mathrm{AG}-\mathrm{AgCl}$ contact surface.

The $\mathrm{Ag}-\mathrm{AgCl}$ prototype test electrode was electroformed from fine (> 99\% pure) $\mathrm{Ag}$ coated $\mathrm{Cu}$ wire using the following method. The wire was cleaned of oil and contaminants with isopropyl alcohol. The clean silver surface was submerged in $0.9 \% \mathrm{NaCl}$ solution along with a counter electrode of the same material. A current of approximately 1 $\mathrm{mA} / \mathrm{cm}^{2}$ was passed through the circuit for approximately 20 seconds. The total electroforming time was extended until the current through the circuit started to decrease. The wire attached to the positive supply should now have a grey/purple colouring. This is the $\mathrm{Ag}-\mathrm{AgCl}$ electrode fully formed. After washing in distilled water for 5 minutes, the electrode was ready for use [65]. 
The data for this first model was not used beyond a basic proof of concept. Basic photographic data was collected from the oscilloscope with a digital camera (Figure 26).

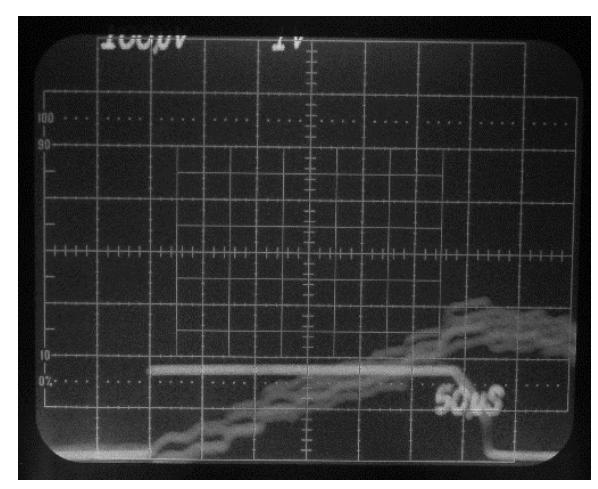

Figure 26. Rectangular trigger pulse and width overlaid with electrode detected pulse, multiple overlapped scans clearly showing steps of activating and deactivating "wire" nodes of Ranvier

For the $\mu \mathrm{P}$ implementation, data was captured using a National Instruments USB interface data acquisition box (NI-USB6251). Analysis were done to check for overall system stability. Specific tests for stability included AP amplitude, AP timing and intermodal timing. The data for analysis was collected using a differential electrode pair made from two individual Ag- $\mathrm{AgCl}$ electrodes (4831Q,Unomedicala/s, Birkerød, Denmark) placed $21 \mathrm{~mm}$ apart on center of snap. The pair was placed in the well such that the center of the differential pair was located over node 20 (PAPER I).

\section{Experiences}

The mixed signal design worked sufficiently well as a proof-ofconcept to support the original hypothesis. Some design limitations that were encountered include a reduction of the pulse width as it propagated. This was unexpected but on further analysis, was found to be the correct behaviour for this circuit design. The same problem was encountered in clock tree distribution nets on large application-specific integrated circuits. Within the limitations of the Paxon configuration, this decay was a problem but did not change the direction of research, only the approach.

Node to node timing was inconsistent due to value tolerances for the resistors $( \pm 5 \%)$ and capacitors $(-20 /+80 \%)$ used in the mixed signal delay circuit. The last main observation was an expected result, whereby 
the propagation delay varied based on the power supply voltage. These results led to the $\mu \mathrm{P}$ approach, which does not suffer from the same deficiencies. The Paxon in its current $\mu \mathrm{P}$ implementation also has a few restrictions based on the design. The I/O update between lower and upper "32 bit" words has a delay of 4 clock cycles, which is $0.125 \mu$ s or $0.7 \%$ of the node to node propagation time at $16 \mu \mathrm{s}$ timing. This is not visible, but is present.

Both the acrylic and epoxy Paxon wells functioned equivalently well, with the $\mathrm{Au}$ wire nodes exhibiting superior stable in the saline environment. Some consideration needs to be given to the epoxy used for casting the well. There are some epoxies that are hydrophilic and will soften over time with exposure to water.

The photographic record Figure 26 form the prototype PMMA well Figure 18 coupling with the small surface electrode Figure 25 clearly shows the stepwise voltage increasing then decreasing in value as the propagating wave "AP" passes under the test electrode.

The Paxon as published in PAPER I has performed in a stable and repeatable manner. This data was collected for one set of 50 samples at one configuration setting and statistically analyzed for stability for mean and standard deviation. The repeatability data is detailed in PAPER I, and summarized in Table 3.

Table 3 . Paxon stability and repeatability data

\begin{tabular}{|l|l|l|}
\hline Parameter & Design intent & Mean +/- range \\
\hline Step to step timing $(\mu \mathrm{s})$ & 60.0 & $61.06+0.59 /-1.04$ \\
\hline Step amplitude $(\mathrm{mV})$ & 5.0 & $5.12 \pm 0.0025$ \\
\hline $\begin{array}{l}\text { DUT Sampled peak value } \\
(\mathrm{mV})\end{array}$ & $\begin{array}{l}\text { Nodes Driven } \\
\text { with 1000 mV }\end{array}$ & $1.50 \pm 0.06$ \\
\hline
\end{tabular}


The Paxon is programmable, and not just with regard to the electrode configuration or position in the well. The generated AP can also be programmed. With a set of DUT electrodes in place, two of the three main parameters, drive amplitude, and active nodes forming the pulse width were varied. The third parameter that can typically be varied is the speed of propagation, or delay between node updates. With this variability, a set of recorded amplitudes were captured and plotted (Figure 27). The resulting plot can be used to configure the AP for an expected detection result, and with that comparisons between different electrode configurations and types can be made.

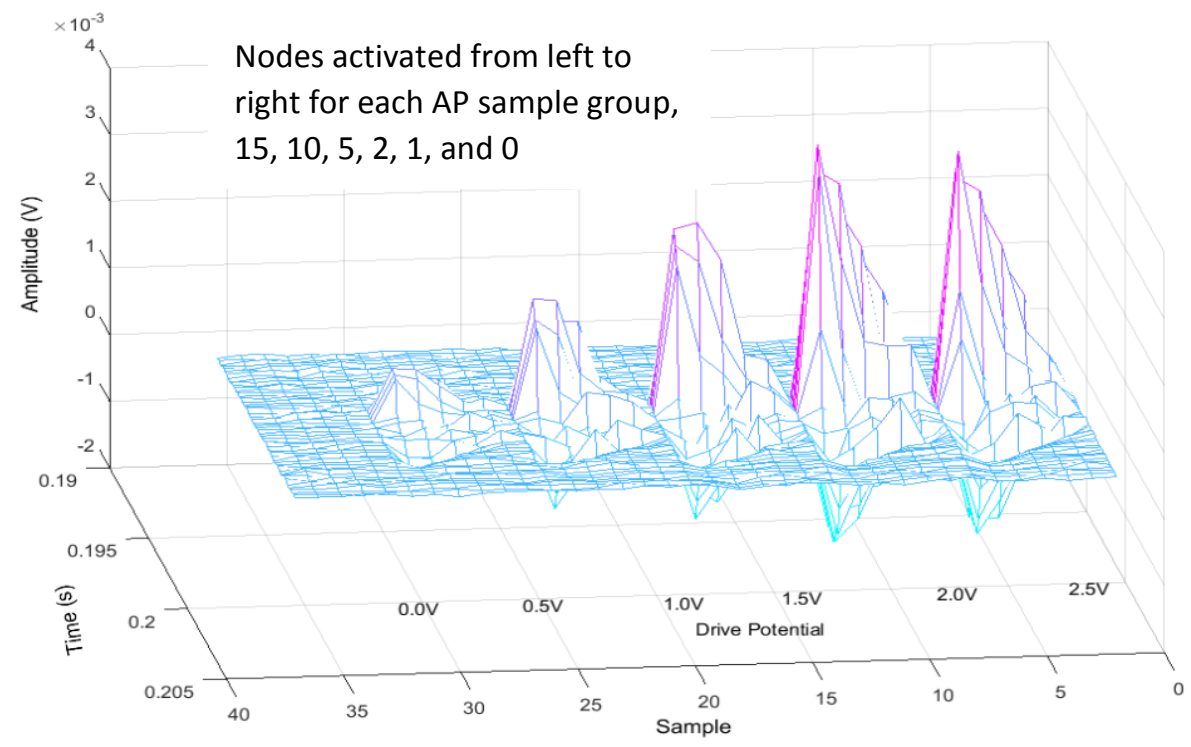

Figure 27. This is an example plot of a detected amplitude with a pair of DUT electrodes. Physical configuration as seen in (Figure 16). 


\section{Electrode Evaluation: FDA vs Paxon}

Testing medical biopotential electrodes on the Paxon required the development of test protocols that are relevant to the electrodes being tested. To limit the possible breadth of testing it was decided to use ECG electrodes from one lot number and manufacturer for the initial tests.

The electrodes selected for testing the Paxon were the commonly used self-adhering skin surface $\mathrm{Ag}$ - $\mathrm{AgCl}$ gel electrode (ARBO-TYKOKendall 31.1925.21, Lot 1185). Two electrodes were used at a time, configured as a differential pair. Testing in the Paxon well was accomplished with the electrodes spaced $21 \mathrm{~mm}$ apart on centres (snapto-snap). This differs from the FDA test configuration [57] of face-toface contact with the pads aligned along their outer edges.

The test sequence was developed to repeatedly test the differential pair for signal capture over a period of time. The differential pair was positioned using an XYZ micrometer with a custom end-effector for rotation the electrode pair while maintaining contact with the tissue mimic bath. The rotation tests were added to evaluate specific manufacturing parameters such as concentricity.

The testing sequence was optimized to run the face-to-face configuration tests first. These were the DC offset test, followed by an AC impedance test at $10 \mathrm{~Hz}$, and finally DC drift. Total test time was approximately 10 minutes to complete all tests. The drift test was based on two DC offset tests run 10 minutes apart. The Paxon tests followed (PAPER II). The Paxon tests started with a DC offset test followed by a DC resistance test, AC impedance test, then the AP capture test set Table 4. Each AP capture test was composed of 50 concurrent AP captures performed within a $60 \mathrm{~s}$ window. The $60 \mathrm{~s}$ window was chosen to enable closely timed AP captures within the first part of the hour long test series. The AP sets were started at time $=\{$ in the initial at times $=\{0,1,2,5,10$, 20, 30, 40, 50, 60 $\}$ minutes. One full Paxon sequence included synchronous rotations of the electrodes. After the AP capture tests were complete, one more set of DC offset, DC resistance, and AC impedance tests was executed. 
Table 4. Paxon test sequence as implemented in PAPER II.

\begin{tabular}{|c|c|}
\hline Activity & Tests \\
\hline Manual & - $\quad$ Pair electrodes, gel to gel connection \\
\hline Manual & $\begin{array}{l}\text { FDA test subset: } \\
\text { • DC offset, DC resistance, AC impedance }\end{array}$ \\
\hline Manual & $\begin{array}{l}\text { - Separate electrodes } \\
\text { - Configure as differential pair } \\
\text { - Place in Paxon well for testing }\end{array}$ \\
\hline Automation & $\begin{array}{l}\text { Paxon Test Sequence } 1: \\
\text { - } \quad \text { Rotation } 0^{\circ}, \\
\circ \quad \mathrm{t}=\{0,1,2,5,10,20,30,40,50,60\} \text { minutes, } \\
\text { - } 50 \mathrm{AP} \text { samples at each time point }\end{array}$ \\
\hline Manual & $\begin{array}{ll}\text { - } & \text { Remove Gel } \\
\text { - } & \text { Remount in Paxon well } \\
\end{array}$ \\
\hline Automation & $\begin{array}{l}\text { Paxon Test Sequence 2: } \\
\text { - } \text { DC offset, DC resistance, AC impedance } \\
\text { - } \\
\text { Rotation } \\
\circ \quad\left\{90^{\circ}, 180^{\circ}, 270^{\circ}, 360^{\circ}\right\} \\
\circ \quad 50 \mathrm{AP} \text { samples } \\
\text { - } \quad \text { DC offset, DC resistance, } \mathrm{AC} \text { impedance }\end{array}$ \\
\hline
\end{tabular}

\section{Observations and Overview of Paxon Data}

Assessments on the DUT electrodes in one case was conducted over a long period of 18 hours (Figure 28). The DC drift over $18 \mathrm{~h}$ was quite obvious, changing from a positive value of $44.5 \mathrm{mV}$ to a value of $10.7 \mathrm{mV}$. The largest drift, however, occurred within the first 10 minutes of testing. $\mathrm{Ag}-\mathrm{AgCl}$ electrodes are considered non-polarizable, and should have a relatively short settling time. However, this is not the case with stainless steel electrodes that are polarizable, which can take hours to settle [66].

Another interesting result came from the rotation tests (Figure 29), where one electrode pair was tested with gel removed. The gel on the electrode had a sensitivity to rotation. With the gel removed, rotation sensitivity was not present. A better evaluation sequence for this test needs to be implemented to reduce the impact of drift and highlight rotational effects. This drift test is logical as the electrode face is centered on the snap, whereas this is not always so for the gel. 


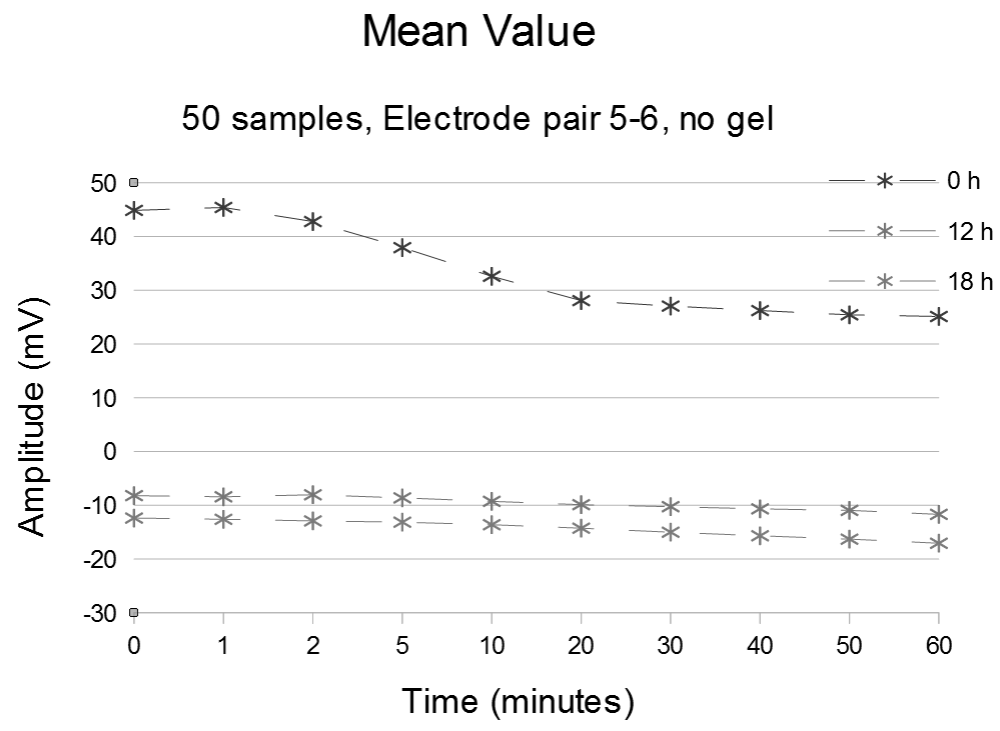

Figure 28. Long time AP capture for DUT electrodes (5-6). DC drift is evident in the sampled time series of DC offset voltages. The largest standard deviation over the complete test cycle (50 AP's) for each group $0 \mathrm{~h}, 12 \mathrm{~h}$ or $18 \mathrm{~h}$ was $1.5 \mathrm{mV}, 0.38$ $\mathrm{mV}$ and $0.32 \mathrm{mV}$ respectively.

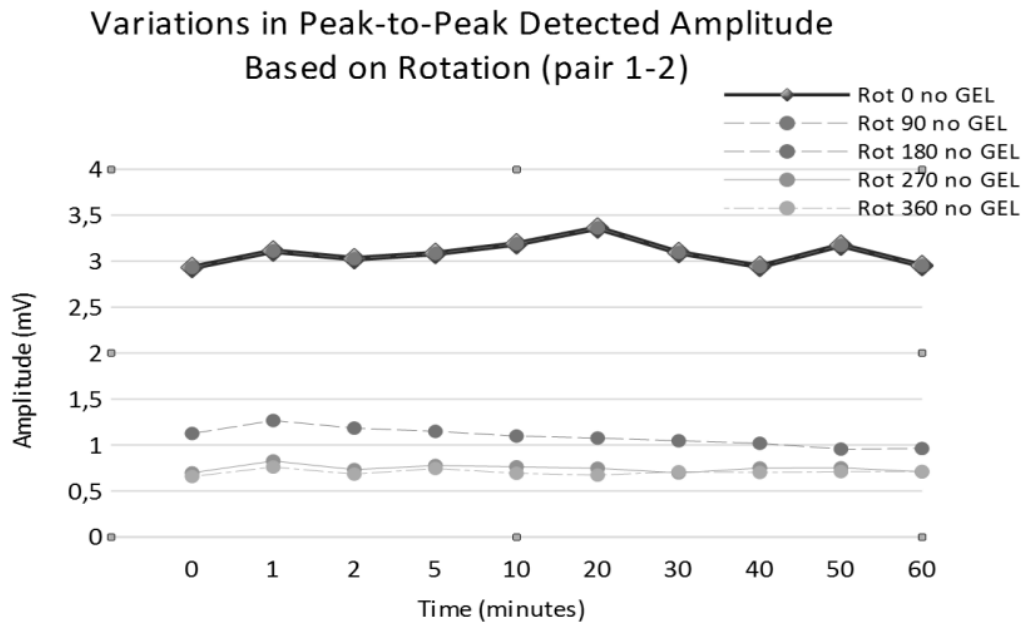

Figure 29. DUT pair 1-2 was tested for rotation stability. All tests were run with gel removed. The standard deviation for each data point was $1.4 \mathrm{mV}$ for $0^{\circ}, 0.4 \mathrm{mV}$ for $90^{\circ}, 0.62 \mathrm{mV}$ for $180^{\circ}, 0.46 \mathrm{mV}$ for $270^{\circ}$, and $0.41 \mathrm{mV}$ for $360^{\circ}$ rotation. 


\section{Computational Neuron Models Applied to DBS}

The neuron models in DBS research are used to be able to assess if an axon of a set diameter has been activated or not by an external stimulation event. The models can be as simple as measuring the intensity of the field $(\mathrm{V} / \mathrm{m})$ or mathematical models that are as accurate and complex as needed to mimick the behaviour of a biological axon. The models in the comparative study in PAPER IV were designed to evaluate the activity of an axon that is exposed to external stimulation. The neuron model should be sensitive to variations in stimulation amplitude, axon diameter, pulse width, and pulse shape.

Marten's neuron model [10] (Model I) is based on the axonal membrane properties and the $\mathrm{Na}^{+}$and $\mathrm{K}^{+}$ion channels as defined by Hodgkin and Huxley [18]. Rushton's g-factor ratios [47] for axon diameter variations are also taken into account in the model. The ion channels initially investigated by Hodgkin and Huxley are considered to be the "fast" channels. A slow $\mathrm{K}^{+}$ion channel was also added to Model I. This model is implemented as a single cable model (PAPER IV, Figure $1 \mathrm{a}, \mathrm{b})$.

McIntyre's neuron model [6] (Model II), has a very strong connection to axon physiology. This model considers the parameters such as myelin lamella wraps and node of Ranvier length. For Model II, the ion channels that are considered are a slow $\mathrm{K}^{+}$ion channel, the fast $\mathrm{Na}^{+}$ ion channel, and a persistent $\mathrm{Na}^{+}$ion channel. This model also considers a constant resting current between the myelin and the axon. This axonal segment is wrapped by a second cable model making it a double cable model (PAPER IV, Figure $1 \mathrm{c}, \mathrm{d}$ )

\subsection{Application Study with Patient Specific Data}

For the patient-specific study in PAPER III, approval by the local ethics committee in Linköping (2012/434-31) was granted, and the patients gave informed consent for the use of their data for this study. Model I was used for this study. The entire simulation was run under the Windows ${ }^{\circledR} 7$ operating system. The neuron model requires, as input, a set of sample lines taken from the electric field. The electric field is simulated using $\mathrm{Comsol}^{\circledR}$, for either a homogeneous volume conductor with a 
conductivity value of $0.123 \mathrm{~S} / \mathrm{m}$ which mimics the bulk grey matter conductivity, or a heterogeneous volume conductor where the conductivity domains within the volume were defined from a preoperative MRI images. The domain conductivity values were assigned based on assessed tissue type (PAPER III). The tissue type segmentation was driven by image intensity thresholding on the average of three layers while restricted to a limited area of interest. In this study, the regions of interest were the ventral intermediate nucleus (VIM) and zona incerta (ZI). The tissue compartments are broken down to grey matter $(\sigma=0.123$ $\mathrm{S} / \mathrm{m})$, white matter $(\sigma=0.075 \mathrm{~S} / \mathrm{m})$, cerebrospinal fluid $(\sigma=2.0 \mathrm{~S} / \mathrm{m})$ and blood $(\sigma=0.7 \mathrm{~S} / \mathrm{m})$.

Patient specific data includes pre-procedural MRI and two post procedural CT scans that were co-registered with Surgiplan ${ }^{\circledR}$. The final lead position was found and the co-ordinates used for analysis. FEM simulations were used to find the electric field from the four leads in both brain models. Comparisons were made between a $0.2 \mathrm{~V} / \mathrm{mm}$ isopotential value and neuron model activation distances.

The distance calculated for the $0.2 \mathrm{~V} / \mathrm{mm}$ isopotential in FEM analysis correspond well with the activation distance of (3.3 to $3.5 \mathrm{~mm}$ ) for the leads based on the neuron model simulations. The configuration used in the neuron model was $3 \mathrm{~V}$ stimulation on a $4 \mu \mathrm{m}$ axon, with a 60 $\mu \mathrm{s}$ pulse width. Other results of note are that voltage stimulation with the homogeneous model resulted in a longer activation distance, while current stimulation resulted in no distance change. Also of note was that leads with smaller contact areas in current mode resulted in greater activation distances. The Comsol ${ }^{\circledR}$ simulations were configured based on the electrode of interest: leads 3389 and SURESTIM 1 (Medtronics, USA), leads 6148 and 6180 (St. Jude, USA). The volume conductor used in PAPER III was configured as a heterogeneous volume conductor, and the DBS lead was positioned within the volume conductor as it was for the patient, with coordinates extracted from post-operative CT images.

The electric field was simulated for a static drive amplitude at the electrode active contact of $1 \mathrm{~V}$ or $1 \mathrm{~mA}$, depending on the study. A set of sample lines were placed within the volume conductor located $0.8 \mathrm{~mm}$ from the center of the source and extending out in steps of $0.1 \mathrm{~mm}$ so that there were 62 sample lines in total Figure 30 . The sample lines extended $11 \mathrm{~mm}$ from the electrode closest point to the line. The data exported from 
$\mathrm{Comsol}^{\circledR}$ was loaded directly into the neuron model software implemented in Matlab ${ }^{\circledR}$ and was plotted in Figure 31.

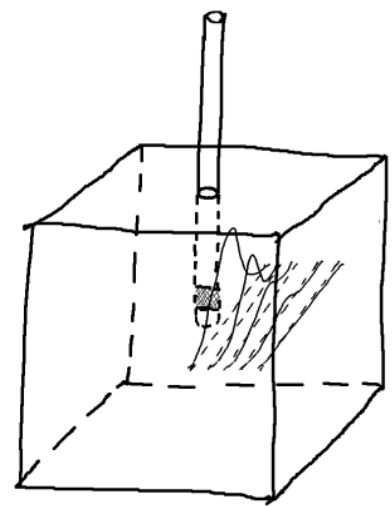

Figure 30. DBS lead in volume conductor with sample lines (dashed line) where electric field will be sampled. Electric field intensity is plotted as solid lines. Lines extend $15 \mathrm{~mm}$ (for PAPER IV, 11mm for PAPSR III) from center of the contact front to back, and are located 1 to $6 \mathrm{~mm}$ from lead center in $0.1 \mathrm{~mm}$ steps. This sample volume in PAPER III is the region of interest and not the complete volume of the brain.

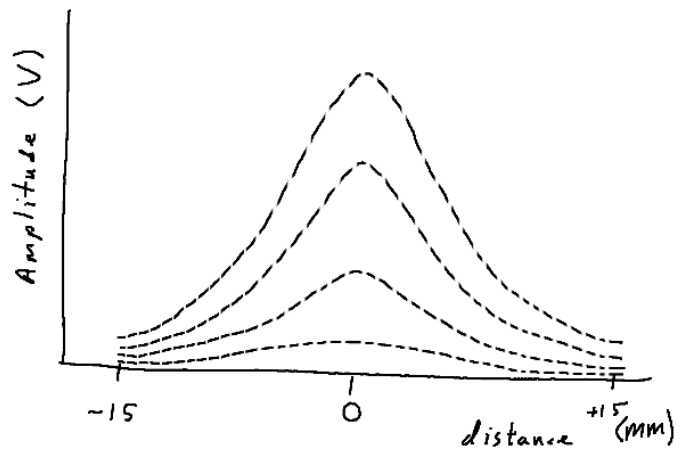

Figure 31. Amplitude of electric field along the path described by the sample lines (ref Figure 30). The lines strongest amplitudes are extracted from the ample lines closest to the source.

Required parameters to the neuron model include the input potential lines, stimulation pulse (shape), axon diameter, stimulation 
amplitude which is a scaling factor ( 0.5 to 5.0 in steps of 0.5$)$ for extracted potential lines, and pulse repetition rate. In this study, a biphasic rectangular pulse was used. The initial phase of the pulse is full amplitude cathodic, with a programmed width, e.g. $60 \mu$ s. The balancing pulse has an amplitude of $10 \%$ and is anodic in polarity (Figure 32). Axon parameters and ion channel properties are calculated based on axon

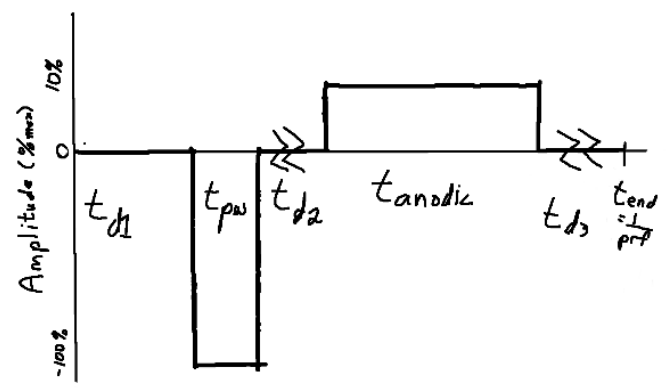

diameter.

Figure 32. Biphasic rectangular pulse used for modulating the amplitude from the sample lines. The delay times are: $t_{\mathrm{d} 1}=120 \mu \mathrm{t}_{\mathrm{d} 2}=400 \mu \mathrm{s}$, and $t_{\mathrm{d} 3}=$ balance of remaining time, the pulse width $\left(t_{\mathrm{pw}}\right)$ is $60 \mu \mathrm{s}$, and $t_{\text {anodic }}=3600 \mu \mathrm{s}$.

The neuron model simulations were solved using the Matlab ${ }^{\circledR}$ ordinary differential equation solver of order 1 to 5, ODE15. The output of this solver is the result of the AP trigger test. The triggering of an AP was treated as a pass/fail event. The triggering event was tested for each axon diameter, distance form lead contact (distance from source), and stimulating potential.

For the study in PAPER III, simulations were carried out in the four cardinal directions (anterior posterior, lateral and medial) along the axial plain, which in this specific study was not normal to the lead axis. An example of results pertaining to the four AP test locations for the 3389 lead is found in Figure 33. 

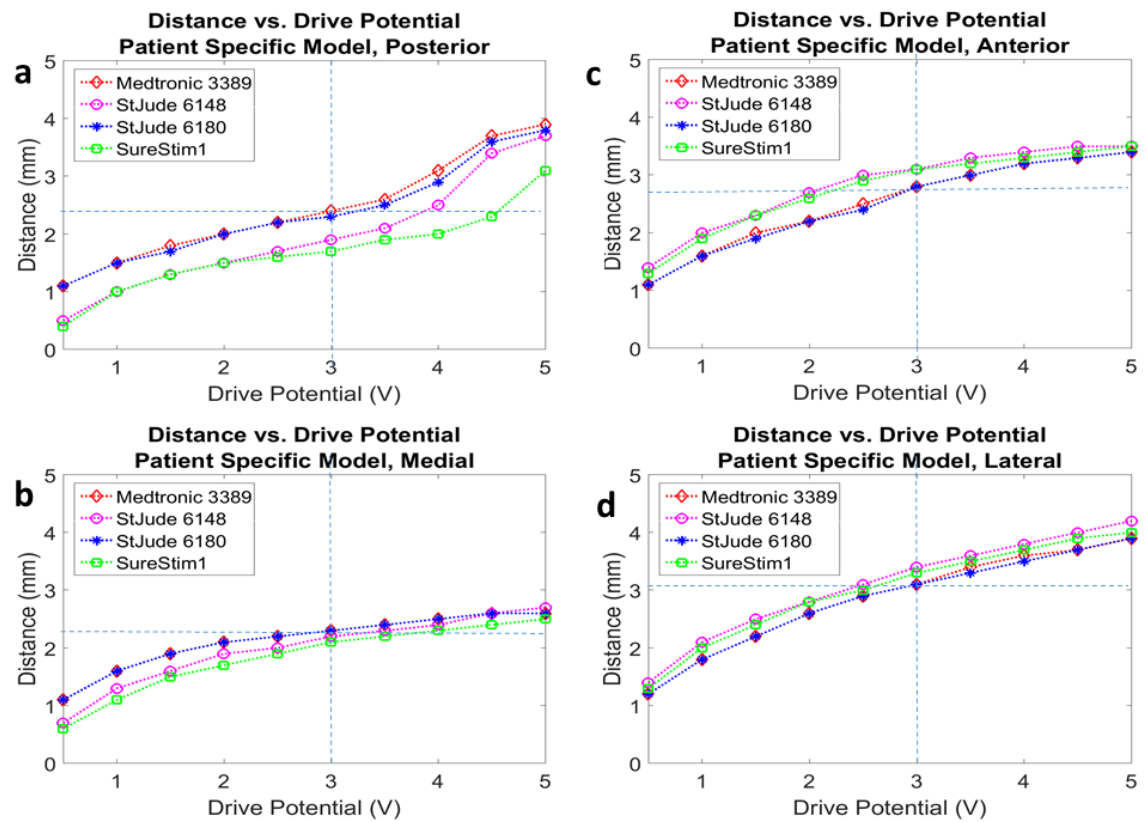

Figure 33. 4.0 $\mu \mathrm{m}$ diameter neuron activation distance vs stimulation voltage curves for a patient specific conductivity model of the brain. All axons were simulated on the axial plane around the lead. The activation distance for a $3 \mathrm{~V}$ stimulation of the $\mathbf{3 3 8 9}$ lead is marked for comparison.

\subsection{Neuron Computational Model Comparison}

A comparison between two neuron models used for DBS simulations. Martens' model, Model I, is described in Åström et al. [10] with the specific intent of studying the maximum distance from a stimulation source that will trigger an AP. Model II is an established model created by McIntyre et al. [6] and implemented by Schmidt [67] with a python scripts for data interfacing, and a bisecting test approach for activation distance to improve the processing efficiency. For this comparison, model inputs were set. as far as possible. to the same set of values to aid in comparison.

For the comparison, a script in Matlab ${ }^{\circledR}$ (R2015b, MathWorks, Natick, MA, USA) was written implementing a current point source that was placed at the center of a homogeneous volume conductor. The 
electric field potential from that point source was calculated along 62 sample lines extending laterally $15 \mathrm{~mm}$ form the axis, and axially starting at $1 \mathrm{~mm}$ and extending out in $0.1 \mathrm{~mm}$ steps from the point source (Figure 30). The voltage along the sample lines was then directly used as input data to both models.

The McIntyre model relies on more physiological measured parameters, and has a limited set of discrete axon diameters. Axons of $(5.7,7.3,8.7,10.0,11.5,12.8,14.0,15.0,16.0 \mu \mathrm{m})$ diameters were defined in the first publication [6]. From Sotiropoulos and Steinmetz [68], $2 \mu \mathrm{m}$ and $3 \mu \mathrm{m}$ axon parameters are available for McIntyre's model and were added to this study. Martens' model is an arithmetic model that was built and verified for axon diameters within a limited range of 1.5 to $10 \mu \mathrm{m}$. The intersection of these two sets was applied to both models. An axon diameter set of 2.0, 3.0, 5.7, 7.3, 8.7, and $10 \mu \mathrm{m}$ were used for the comparison.

The amplitude vectors from the sample lines were modulated according to specific envelop waveshapes. These consisted of a set of simple monophasic cathodic pulses with the following shapes: rectangular, sinusoidal, and triangular, and one biphasic pulse based on the monophasic rectangular pulse with an anodic counter pulse of $10 \%$ amplitude with a longer duration (Figure 31,32). A pulse width of $60 \mu \mathrm{s}$ with a repetition rate of $130 \mathrm{~Hz}$ was also used for both models. The biphasic pulse is commonly what is applied to live tissues as this pulse shape injects a net-zero current into the tissue over one pulse repetition cycle.

With the input parameters defined, each neuron model was then run under Ubunto $^{\circledR}$ (14.04 LTS, 64bit, Linux ${ }^{\circledR}$ ) operating system. McIntyre's model was run as a set of Python ${ }^{\circledR}$ (release 2.7.6, Python Software Foundation, OR, USA) scripts that called and executed functionality within $\mathrm{NEURON}^{\circledR}$ (release 7.3, Yale University, New Haven, CT, USA) (Figure 34). Martens' model was run as a set of Matlab $^{\circledR}$ scripts calling core calculation functional blocks (Figure 35). Details of the models are found in PAPER IV, [6] and [10] respectively.

Data trends from the McIntyre model (2002) compared to Martens' model ([10] show a convergence as the axon diameters get larger. Adding in the two smaller axon diameters from [68], there is a 
second convergence as the axons get smaller. One possible reason for the differences in activation distance has to do with the differences in the models (Paper IV, Figure 3) and which ion channels are implement. These slight differences in structure will change the behaviour of the model under stimulation. The models also differ in the implementation of the node to node length calculation. Model I calculated parameters dependant on the axon diameter, while Model II used physiological data for more of its inputs parameters, and calculates the rest.

Simulations were run for a 3389 lead with a monophasic rectangular pulse of 60 and $100 \mu \mathrm{s}$ width for an axon diameter of $5.7 \mu \mathrm{m}$ (Figure 36) and compared to published data [60].

It is interesting to note that Model I was designed specifically for DBS activation distance simulations, and the parameters were adjusted to best fit published data for axons in the range of $1.5 \mu$ to $10 \mu$ in diameter. Model II was designed to investigate the after potentials (refractory period recovery), for peripheral neurons and therefore answers a very different question.

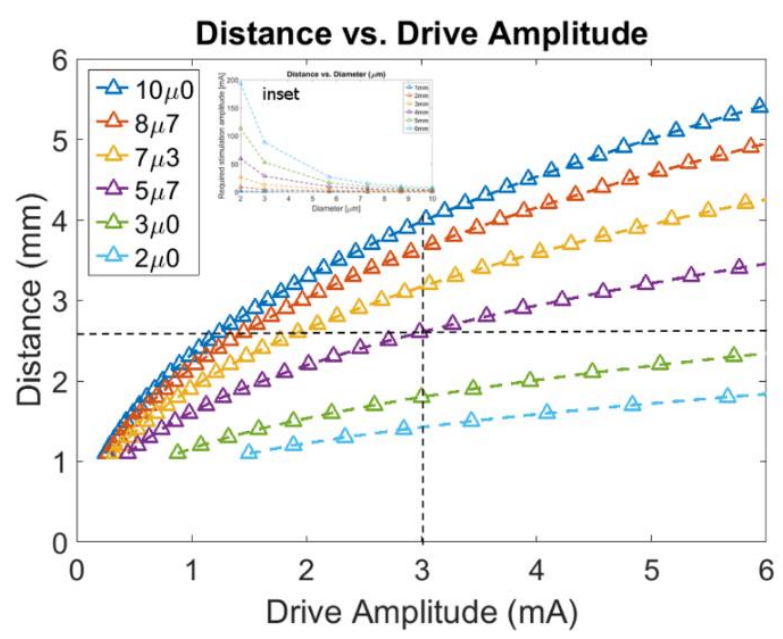

Figure 34 Model II activation distance for a homogeneous volume conductor $(\sigma=0.3 \mathrm{~S} / \mathrm{m})$ driven by a point source. The inset presents the data as it is presented by the model, and the main figure is that data formatted to display in the same way as Model I. 


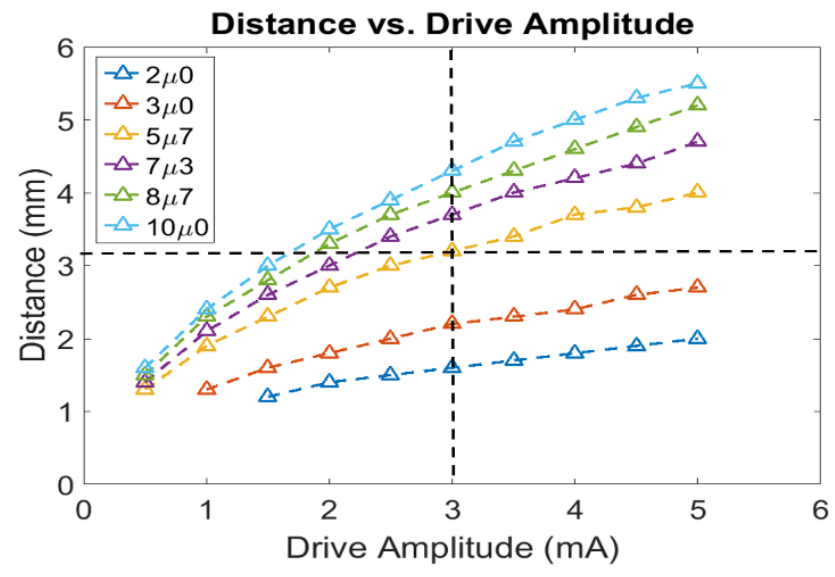

Figure 35. Activation distance simulations for Model I for a homogeneous volume conductor $(\sigma=0.3 \mathrm{~S} / \mathrm{m})$ driven from a point source. The $5.7 \mu \mathrm{m}$ diameter axon is highlighted as a reference.

Distance vs Drive Amplitude (V)

3389 lead, 5.7 Imum, $0.3 \mathrm{~S} / \mathrm{m}$, monophasic rectangular

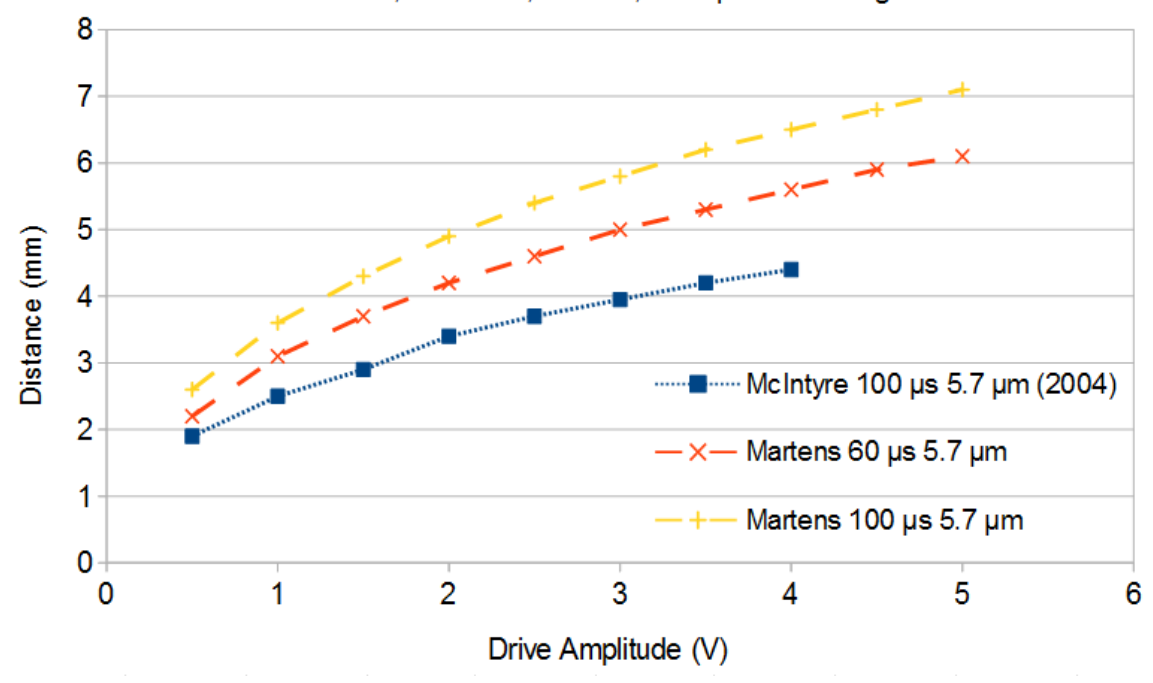

Figure 36. Comparison of simulated activation distance from a voltage stimulation source for an axon of $5.7 \mu \mathrm{m}$ diameter from the two neuron simulation models under varied conditions. McIntyre 2004 data from [60]. 


\section{Summary of Papers}

\subsection{Paper I}

The testing and construction of a generalized action potential generator, Paxon, is described in this paper. The design intent of the Paxon was to develop an evaluation platform for biopotential electrodes, as well as a platform upon which quantitative studies of different electrodes can be made and compared. The requirements for this evaluation platform are stability, and repeatability of the synthesized AP pulse as well as sufficient flexibility to allow the evaluation of a large range of electrode types.

This was accomplished by constructing a test well with an integral structure that is fashioned after one of the larger axons commonly found in the human body, an A-Fibre of $20 \mu \mathrm{m}$ diameter. Under test conditions, the Paxon delivered an electric field with the required stability over both short and long time periods, as well as being programmable.

The evaluation results for the Paxon were recorded by a set of ECG electrodes in differential configuration, as well as by direct measurement with test equipment. From the trigger signal, the AP started with a programmed delay of $196.2 \pm 0.06 \mathrm{~ms}$. The positive peak, with 40x gain differential amplifier, measured $1.50 \pm 0.06 \mathrm{~V}$ when the Paxon was configured for a pulse width of 5 active nodes and a drive potential of $1 \mathrm{~V}$. The node to node propagation time was programmed to $60 \mu \mathrm{s}$ and was measured to be $61.06+0.59$ to $-1.04 \mu \mathrm{s}$. Amplitudes at the recording electrodes were $50 \pm 1.5 \mu \mathrm{V}$. 


\subsection{Paper II}

Five pairs of electrodes from one batch/lot were evaluated using the Paxon. The tests were performed in a specific sequence based on the action on the electrode, e.g. face-to-face contact first, then immersion into the test well. This order was selected due to swelling of the gel in the second step. Once that initial requirement was met, then the test sequence was designed to take best advantage of the type of test performed, e.g. DC test, followed by pulse tests, then rotation and pulse, etc. The first test set included as much of the FDA test sequence as possible, followed by the Paxon evaluation, and where possible, the FDA test set was again assessed.

The biopotential electrodes were evaluated in pairs for differences in DC offset, drift and settling, with both short and long drift variations measurable. Sensitivity to rotation was also measured, as the pads were not manufactured symmetrically. It was noted that this test was not possible with the FDA configuration. The Paxon was configured for $60 \mu$ s inter node step timing, a pulse of 5 nodes length, and a drive strength of $2.9 \mathrm{~V}$.

The evaluations showed that there were differences in the paired electrodes. DC offset and drift were different for each pair. Rotation also resulted in differences in acquired signal amplitude with pair (1-2) having a mean value of 5.3 and a standard deviation of $8.9 \mathrm{mV}$ across all rotation angles $(0,90,180,270$, and 360 degrees). One longer test of 18 hours on an electrode pair depicts the settling curve where the DC offset changed from $45.5 \mathrm{mV}$ at 0 hours to $12.4 \mathrm{mV}$ at 18 hours. Even during the eighteenth hour, the electrodes were still drifting towards a $0 \mathrm{mV}$ offset. 


\subsection{Paper III}

This paper presents a comparison simulation study of four lead designs. Two leads are steerable (Medtronic SureStime1 and St Jude 6180), and two leads are non-steerable (Medtronic 3389 and St Jude 6148). The comparison was made, focussing on the distance from the electrode that a specific axon diameter is triggered.

In this study the electric field extending from the DBS lead active contact is simulated with a finite element analysis tool, $\mathrm{Comsol}^{\circledR}$. The output from this simulation is used for neuron model simulations, which estimate the activation distance for a specific set of parameters e.g. axon diameter, pulse width, and stimulation amplitude. Here we showed the feasibility of remove the dependence on the neuron model and replace that with a fixed isopotential level in the $\mathrm{Comsol}^{\circledR}$ electric field calculations. The isopotential level should be selected based on DBS pulse width and axon diameter.

The electric field resulting from the leads are modeled for both a homogenous environment and a patient specific, heterogeneous, environment for both current and voltage controlled stimulation. The leads were placed in the patient specific target, the ZI target, and a virtual target, VIM for the simulations. The study includes patient data and was approved by the local ethics committee in Linköping (2012/434-31). The patients gave informed consent for the use of their data in this study.

The neuron model simulations were prepared for all configurations Testing was done with drive potentials $\{0.5,1.0,1.5,2.0$, 2.5, 3.0, 3.5, 4.0, 4.5, 5.0, $\mathrm{n}=10$, stimulation modes $\{\mathrm{V}, \mathrm{mA}\} \mathrm{n}=2$, tissue model $\{$ homogeneous and heterogeneous $\}, \mathrm{n}=2$, and four lead positions $\mathrm{n}=4$, and finally for axon diameters of $\{1.5,2.0,2.5,3.0,3.5,4.0,4.5$, $5.0\}$, and $n=8$. A resulting total of 823 simulation runs were performed. The data was analysed and configured to map with the Comsol ${ }^{\circledR}$ EF simulations. Comparisons between the neuron model and an isopotential level of $0.2 \mathrm{~V} / \mathrm{mm}$ resulted in distance estimates which were the same as if a $4.0 \mu \mathrm{m}$ axon were stimulated. 


\subsection{Paper IV}

Prediction of the activation distance for DBS simulations is typically made using neuron models. Two models are compared for their activation distance. Input variables for this comparison are stimulation amplitude current, potential values extracted from an electric field, both point source and finite element analysis methods, pulse width and repetition rate, and finally waveshape. Specifically monophasic rectangular, sinusoidal and triangular and one biphasic rectangular waveshapes were evaluated. While both models answer the question of activation distance for a specific current and axon diameter, both models solved that problem by distinctly different means.

Model I is a single cable model that implements node of Ranvier currents related to leakage current, fast and slow $\mathrm{K}^{+}$currents, and the fast $\mathrm{Na}^{+}$current. Model I addressed the distance question with input of current and axon diameter. Model II is a double cable model, with the second cable model wrapping around an inner model and implementing circuit elements over the myelinated segment which has an active current node within it. This model's node of Ranvier takes into account the slow $\mathrm{K}^{+}$, fast $\mathrm{Na}^{+}$, persistent $\mathrm{Na}^{+}$and leakage currents. Model II solves for the stimulation current needed to activate a specific axon diameter at a fixed distance from the source.

To obtain the comparison, each model was run in its respective, intended environment. The input parameters used were identical and generated from a single source. Model II consistently predicted distances that were shorter than Model I for all axon diameters, with the exception of the $2.0 \mu \mathrm{m}$ diameter axon. Both models responded to changes in waveshape in the same manner. There was minimal to negligible differences observed for the rectangular pulse (monophasic to biphasic), with progressively shortened activation distances for sinusoidal and triangular waveshapes, respectively. 


\section{Discussion and Conclusions}

An exploration of both physical and computational neuron models was made. The Paxon was developed into a working evaluation platform for biopotential electrodes. Two computational neuron models used for DBS simulations (Model I [10] and Model II [6]) were compared against each other. One of the goals of this work is to remove the dependency DBS activation volume calculations have on the neuron models and replace this with an isopotential value within the electric field simulations, which reduced the overall computation time, and quickly enhances visualization of the activation distance or volume. Finally, assessments of simulated axonal activation in both homogeneous and patient-specific, heterogeneous brain models were completed for four DBS lead designs.

\subsection{Paxon}

The Paxon's development presented a challenge with its many technical details. To enable mechanical assembly of the physical model, a larger axon diameter was selected, e.g. $20 \mu \mathrm{m}$. This selection imposed a set of fixed parameters e.g. $2 \mathrm{~mm}$ internodal spacing, $\sim 120 \mathrm{~m} / \mathrm{s}$ propagation speed based on Rushton's work [47]. A similar set of equations are found in both computational models evaluated in PAPER IV $[6,10]$. The main difference was that the Paxon implements a fixed axon diameter while the computational models calculate the parameters dynamically. The Paxon only implements a digital node function. The electrode area integrates the signal from multiple Paxon nodes which results in a smooth recorded waveform. The larger the electrode, the lower the spatial resolution $[43,56,69]$ and the smoother the curve. The smaller surface area electrodes (Figure 25) very clearly demonstrated this effect, on the captured signal recording shown in Figure 26. The results from the small surface area electrode were not smooth as initially expected but have a very clear step pattern with the activity of the neighbouring nodes, which is the correct result. With the exception of patch clamp electrodes which are exposed to the full transmembrane potentials, recording electrodes such as ECG, EEG, needle electrodes and DBS electrodes can be evaluated with the Paxon.

The selection of the electronics, node drivers, and $\mu \mathrm{P}$, imposed its own limitations. The current configuration is limited to 40 mimicked 
nodes of Ranvier (ATXmega128A1 I/O limitation). This appears to be sufficient for use in the analyses made, although a longer axonal segment would be interesting to explore. The choice of drive controller set the boundaries for propagation speed and overall timing stability, PAPER I [70].

The Paxon electrode materials also highlighted a critical set of design choices, where $\mathrm{Cu}$ proved to be unstable for this application. The second implementation used $\mathrm{Au}$ for the electrode [71]. The Au has remained stable without intervention. The Au Paxon well has over $100 \mathrm{~h}$ of activity with no signs of deterioration. Electrode materials need to withstand a certain amount of current imbalance. For example an Ag$\mathrm{AgCl}$ electrode will fail over time if there is a direct current flow through the electrode. Electrodes generally work best when there is a net-zero current through the electrode over time, which is the case with live tissue signal sources. Stability and recovery form strong polarization can damage the electrode interface, which is the motivation for the defibrillator recovery test in the ECG assessment specifications [50, 51].

While the same demands of net-zero current flow are placed on stimulating electrodes, e.g. DBS and pacemaker electrodes, they must also carry a higher current. Stimulating electrodes are typically made from materials that are more resilient to their environment and under continuous usage, such materials are Pt or Pt-Ir that can inject large currents without self damage. Bio-compatible polymers such as those of the PEDOT family of materials are also being investigated for this high current stability property [72, 73].

Future directions for the Paxon include the design of a flexible well or strip using silicon rubber instead of hard epoxy. The flexible well would allow studies of deformation of the axon path, and how the electric field distortion affects the recorded result. Development and testing of a flexible strip electrode e.g. based on PEDOT or Au on Mylar, which could be used with any suitable container, would allow for the model to easily interface to specialty electrodes such as the cuff electrode. Decreasing the axon diameter, and its attendant properties, and possibly increasing the number of nodes with a different $\mu \mathrm{P}$ or even a field programmable gate array (FPGA) would allow for multi electrode assessments such as is found in the DBS lead. Another major change would be to mimic the full function of the node of Ranvier with its AP regenerating properties, allowing the Paxon to be triggered in the same 
way as neuronal tissue would be from an external electrode. Another option would be to implementing electronics at the node driver that more closely follows the AP waveshape at the node of Ranvier, as opposed to the rectangular pulse currently implemented.

\subsection{General Electrode Evaluations using the Paxon}

To accommodate use for bio-potential electrode evaluation the base Paxon design (PAPER I) was further modified, as per PAPER II. One set of features that were added are the basic FDA [51] tests for DC offset and DC resistance. To create a $10 \mathrm{nA}$ galvanically isolated current source that could be turned on and off a phototransistor, the 4N26 [74], with a feedback loop for illumination source intensity control was used.

Early observations from tests run in PAPER I revealed that the snap type surface ECG electrodes with gel were not concentrically made. There were variations on the location of the gel and button within the surround. To determine how sensitive these variations were, a synchronous rotary mechanism was built (PAPER II). Full automation of the Paxon tests was implemented and controlled from a LabVIEW ${ }^{\circledR}$ program. This approach was shown to be highly configurable and yet relatively easy to set-up and use. This is quite different form the existing test benches that require skill and knowledge of the equipment involved, e.g. FDA configuration, although this should be possible with modifications to cuff electrode test configurations $[43,51,56]$.

As the device is currently configured in Paper II, it is possible to use the Paxon to evaluate any electrode in recording mode. Even cuff electrodes can be partially unrolled and placed on the bottom of the well over the axon nodes, resulting in a restricted current path, and apparent increase in captured signal. DBS electrodes can likewise be placed within the test well for recording the AP. Future tests can be made with a DBS electrode in the existing well for evaluating the sensitivity of these electrodes and comparison between the electrodes. Comparisons between the results from Paxon tests (PAPER II) and the computational neuron models (PAPER IV) would also be possible.

Ultimately building a database of electrodes evaluated using the same hardware and under the same conditions will be beneficial. With this type of approach, quantitative studies and cross electrode comparisons can be made. A set of other electrodes (5 pairs each of Vatus 
ECG electrodes 241008 and Nikomed 4540) have already been tested as a start to building a database. A further refinement that is planned is the inclusion of a flexible node of Ranvier strip that can be placed in any chamber and in any orientation as opposed to what is currently implemented (PAPER II). While this will increase the overall application range of the Paxon, there are some possible limitations with the flexible axon. The first is the material and dimensions. If printed electronics are used, the feature size will increase. Lithographic techniques may be required to reach the small features required. A potential drawback to using a flexible axon, however, is that it would be harder to define where the axon is relative to the electrode.

Some exploration into other materials for the Paxon's nodes of Ranvier are also under investigation. The optimal material would have a low energy to eject electrons, low interface impedance, be stable to small continuous currents, and able to inject larger currents without degradation [71]. Some materials that should be tested include $\mathrm{Au}$, carbon, $\mathrm{Ag}-\mathrm{AgCl}$ and PEDOT [72, 73].

\subsection{Neuron Model Evaluations}

The application of neuron models to DBS is a demanding task. The simplest neuron models will not correctly describe the function of the axon $[18,47]$, whereas highly complex models can become difficult to understand, manage and configure correctly $[6,10]$ or rely on detailed data that is sparse or difficult to collect [6].

In Paper IV, Model I [10] is assessed against Model II [6]. The activation distance is compared based on an axon's diameter, stimulation amplitude and stimulation pulse envelope as the working constraints. The models calculated activation distances that have equivalent trends, but with different activation distances. The distance difference from Model I ranged from +0.5 to $-0.45 \mathrm{~mm}$ over the entire set of axons, and modulating envelopes, for a pulse width of $60 \mu \mathrm{s}$. The solvers were set to stop when the calculated distance difference fell below $0.01 \mathrm{~mm}$. The activation distances for the $5.7 \mu \mathrm{m}$ axon for Model I was $3.2 \mathrm{~mm}$ (Figure 35), and for Model II was $2.6 \mathrm{~mm}$ (Figure 34) which is in line with the distances previously published [6, 10, 60, 67, 75].

For standard simulations, the application of the neuron model may not be necessary if a correlated set of isopotential values to axon 
diameter and pulse width are prepared. When a different set of conditions are applied, such as pulse shape or other parameters are changed, then there is value in applying the computational neuron model to verify the correlations for that specific set of conditions. Initially some form of tabular results should suffice, such as those in Åström et al. [10], but eventually as the number of parameters or environments become large enough, a simple statistical equation can be developed to replace the tables, and allow for quick computation of activation distance directly from the FEM electric field analysis.

The application of the computational neuron models does have a few critical differences. For example, Model I relied on the FEM output having sample lines that are long enough to stay out of numerical methods boundary conditions, these lines are resampled within the neuron analysis program to place a sampled potential at the center of the compartment of interest, e.g. node of Ranvier. Model II applied compartment locations to the EF volume to extract the potential needed without resampling the input data.

In conclusion, the Paxon has met the basic requirements for evaluating biopotential electrodes such as the self-adhering ECG electrodes that were used for the bulk of the evaluations performed. The model is versatile and can be adapted to evaluate other electrode types. The fundamental driving equations behind the development of the Paxon have the same starting point as those implemented in existing DBS neuron computational models $[18,47]$. The approach to the question of assessing biopotential electrodes, whether for detection or stimulation, will continue to evolve as more knowledge is gathered about the anatomical and physiological organisation of the active tissue. Concurrently, a better understanding of the electrode interface will also allow a better understanding of what models are required to optimally mimic the target tissues of interest. 


\section{References}

1. SCHILLER AG. 19742016 [cited 2016 Oct 24]; Corporate www site]. Available from: http://www.schiller.ch/kh/en/cardiovit-ft-1maximum-performance-compact-electrocardiograph.

2. Dictionary.com. The American Heritage ${ }^{\circledR}$ Science Dictionary. 2016 [cited 2016 October 3]; Available from: http://www.dictionary.com/browse/model.

3. Malmivuo, J.A., J. Honkonen, and K.E. Wendel, Did Jan Swammerdam Do the First Electric Stimulation over 100 Years before Luigi Galvani?, in XIII Mediterranean Conference on Medical and Biological Engineering and Computing 2013, L.M. Roa Romero, Editor. 2014, Springer International Publishing. p. 13-16.

4. Frize, M., Laura Bassi and Science in 18th Century Europe. 2013, Berlin , Germany: Springer-Verlag Berlin Heidelberg. 196.

5. Holmes, F.L., The old martyr of science: the frog in experimental physiology. J Hist Biol, 1993. 26(2): p. 311-28.

6. McIntyre, C.C., A.G. Richardson, and W.M. Grill, Modeling the Excitability of Mammalian Nerve Fibers: Influence of Afterpotentials on the Recovery Cycle. Journal of Neurophysiology, 2002. 87(2): p. 995-1006.

7. unknown. Willem Einthoven ECG.jpg [cited 2016 Oct 24]; 2006:[Available from: https://commons.wikimedia.org/wiki/File:Willem_Einthoven_E CG.jpg.

8. Latorre, M., Action Potential Generator and Electrode Testing, in Department of Biomedical Engineering. 2015, Linköping University Linköping University Electronic Press. p. 44.

9. Association, E.P.s.D. Parkinson's disease - what is Parkinson's. [web page] 20172017 [cited $201717 \mathrm{Feb}$; Available from: http://www.epda.eu.com/en/pd-info/aboutparkinsons/?Opentab $=\mathrm{c} 0,2$.

10. Åström, M., et al., Relationship between Neural Activation and Electric Field Distribution during Deep Brain Stimulation. IEEE Trans Biomed Eng, 2015. 62(2): p. 664-72.

11. Naoshi, D.J.D.C.L.D. 2004. 
12. Second Sight Medical Products Inc. Argus II. 19982016 [cited 2016 Oct 20]; Available from: corporate: http://www.secondsight.com/history-en.html https://en.wikipedia.org/wiki/Argus_retinal_prosthesis.

13. Barron, S.L., Development of the Electrocardiograph in Great Britain. British Medical Journal, 1950. 1(4655): p. 720-725.

14. Kandel, E.R., Principles of neural science. 5th ed. 2013, New York: McGraw-Hill. 1, 1709 p.

15. Tortora, G.J. and S.R. Grabowski, Principles of anatomy and physiology. 10th ed. 2003, New York: John Wiley \& Sons. xxxii, 1104, $97 \mathrm{p}$.

16. Malmivuo, J. and R. Plonsey, Bioelectromagnetism : principles and applications of bioelectric and biomagnetic fields. 1995, Oxford University Press: New York. p. xxii, 482 p.

17. Waxman, S.G., J.D. Kocsis, and P.K. Stys, The axon : structure, function, and pathophysiology. 1995, New York: Oxford University Press. xv, 692 p., 2 p. of plates.

18. Hodgkin, A.L. and A.F. Huxley, A quantitative description of membrane current and its application to conduction and excitation in nerve. J Physiol, 1952. 117(4): p. 500-44.

19. Waxman, S.G., J.D. Kocsis, and P.K. Stys, The Axon: Structure, Function, and Pathophysiology. 1995: Oxford University Press.

20. Squire, L.R.e., Andrew F. Huxley. The History of Neuroscience in Autobiography, 2004. 4: p. 282 - 318.

21. Hemm, S. and K. Wardell, Stereotactic implantation of deep brain stimulation electrodes: a review of technical systems, methods and emerging tools. Med Biol Eng Comput, 2010. 48(7): p. 611-24.

22. Klooster, D.C., et al., Technical aspects of neurostimulation: Focus on equipment, electric field modeling, and stimulation protocols. Neurosci Biobehav Rev, 2016. 65: p. 113-41.

23. Speedie, A., et al., Long-term Mortality in Patients with Permanent Pacemaker Implantation. J Assoc Physicians India, 2016. 64(9): p. 18-22.

24. Begic, Z., et al., The Use of Continuous Electrocardiographic Holter Monitoring in Pediatric Cardiology. Acta Inform Med, 2016. 24(4): p. 253-256. 
25. Moini, C., et al., [Cardiac permanent pacemaker after transcatheter aortic valve implantation: A predictive and scientific review]. Ann Cardiol Angeiol (Paris), 2016.

26. Farmer, A.D., A. Albu-Soda, and Q. Aziz, Vagus nerve stimulation in clinical practice. Br J Hosp Med (Lond), 2016. 77(11): p. 645-651.

27. Dhillon, M., et al., Efficacy of Transcutaneous Electric Nerve Stimulation on Parotid Saliva Flow Rate in Relation to Age and Gender. J Dent (Shiraz), 2016. 17(3): p. 164-70.

28. Zheng, J., et al., [Exploration Research of Treatment Effect Improvement of Transcutaneous Electrical Nerve Stimulation Using Parameter-changing Chaotic Signal]. Sheng Wu Yi Xue Gong Cheng Xue Za Zhi, 2015. 32(5): p. 1031-7.

29. American Speech-Language-Hearing Association. Cochlear implants [Technical Report]. 2004 [cited 2017 March 19]; Available from: http://www.asha.org/policy/TR200400041/\#sec1.3.

30. Wells, J., et al., Lasers Stimulate New Techniques in Nerve Studies, in BioPhotonics. 2006, Photonics Nedia.

31. Shapiro, M.G., et al., Infrared light excites cells by changing their electrical capacitance. Nat Commun, 2012. 3: p. 736.

32. Deisseroth, K., Optogenetics: 10 years of microbial opsins in neuroscience. Nat Neurosci, 2015. 18(9): p. 1213-25.

33. Julian, F.J. and D.E. Goldman, The effects of mechanical stimulation on some electrical properties of axons. J Gen Physiol, 1962. 46: p. 297-313.

34. Wright, C.J., J. Rothwell, and N. Saffari, Ultrasonic stimulation of peripheral nervous tissue: an investigation into mechanisms. Journal of Physics: Conference Series, 2015. 581(1): p. 012003.

35. Norton, S.J., Can ultrasound be used to stimulate nerve tissue? Biomed Eng Online, 2003. 2: p. 6.

36. Kupers, R., et al., Transcranial magnetic stimulation of the visual cortex induces somatotopically organized qualia in blind subjects. Proc Natl Acad Sci U S A, 2006. 103(35): p. 13256-60.

37. Loeb, J. and W.F. Ewald, Chemical Stimulation of Nerves. Journal of biological Chemistry, 1916. 25.

38. Koch, C., Biophysics of computation : information processing in single neurons. Computational neuroscience. 1999, New York: Oxford University Press. xxiii, 562 p. 
39. Carnevale, N.T. and M.L. Hines. NEURON software. [cited 2016 2016-11-29];

Available from: http://www.neuron.yale.edu/neuron/download/compile_linux.

40. Roy, G., A Simple Electronic Analog of the Squid Axon Membrane: The NEUROFET. Biomedical Engineering, IEEE Transactions on, 1972. BME-19(1): p. 60-63.

41. Lewis, E.R., Using electronic circuits to model simple neuroelectric interactions. Proceedings of the IEEE, 1968. 56(6): p. 931-949.

42. Lewis, E.R., An electronic model of neuroelectric point processes. Kybernetik, 1968. 5(1): p. 30-46.

43. Rieger, R., M. Schuettler, and S.C. Chuang, A device for emulating cuff recordings of action potentials propagating along peripheral nerves. IEEE Trans Neural Syst Rehabil Eng, 2014. 22(5): p. 937-45.

44. Goldin, A.L., Mechanisms of sodium channel inactivation. Curr Opin Neurobiol, 2003. 13(3): p. 284-90.

45. Raman, I.M. and B.P. Bean, Inactivation and recovery of sodium currents in cerebellar Purkinje neurons: evidence for two mechanisms. Biophys J, 2001. 80(2): p. 729-37.

46. Oliva, C., V. Gonzalez, and D. Naranjo, Slow inactivation in voltage gated potassium channels is insensitive to the binding of pore occluding peptide toxins. Biophys J, 2005. 89(2): p. 100919.

47. Rushton, W.A., A theory of the effects of fibre size in medullated nerve. J Physiol, 1951. 115(1): p. 101-22.

48. Wesselink, W.A., J. Holsheimer, and H.B. Boom, A model of the electrical behaviour of myelinated sensory nerve fibres based on human data. Med Biol Eng Comput, 1999. 37(2): p. 228-35.

49. Chi, Y.M., T.P. Jung, and G. Cauwenberghs, Dry-contact and noncontact biopotential electrodes: methodological review. IEEE Rev Biomed Eng, 2010. 3: p. 106-19.

50. Association for the Advancement of Medical Instrumentation, Disposable ECG electrodes ANSI/AAMI EC12:2000/(R)2010. 2000, Arlington, VA, USA: Association for the Advancement of Medical Instrumentation

51. Food and Drug Administration United States of America. UCM080228. [PDF] 2014 2014_04_01 [cited 2015 2015_08_10]; Available from: 
http://www.fda.gov/downloads/MedicalDevices/DeviceRegulati onandGuidance/GuidanceDocuments/UCM080228.pdf.

52. Webster, J.G., Medical Instrumentation: Application and Design 3rd Edition. 3rd ed. 1998, Canada and United States of America Simultaneously: John Wiley \& Sons, Inc. 691

53. Persson, J., Digital Signalanalys MedMedicinska Tillämningar. 1993, Linköping, Sweden: Linköping Univsersity

54. Bradley, J.R., The Electrical Conductivity of Tissues, in The Biomedical Engineering Handbook, Second Edition. 2 Volume Set. 1999, CRC Press.

55. Yoshida, K., G.A. Kurstjens, and K. Hennings, Experimental validation of the nerve conduction velocity selective recording technique using a multi-contact cuff electrode. Med Eng Phys, 2009. 31(10): p. 1261-70.

56. Andreasen, L.N.S., J.J. Struijk, and M. Haugland, An artificial nerve fiber for evaluation of nerve cuff electrodes. Proceedings of the 19th Annual International Conference of the Ieee Engineering in Medicine and Biology Society, Vol 19, Pts 1-6, 1997. 19: p. 1997-1999.

57. United States of America Food and Drug Administration. UCM080228. [PDF] 2014 2014_04_01 [cited 2015 2015_08_10]; Available from: http://www.fda.gov/downloads/MedicalDevices/DeviceRegulati onandGuidance/GuidanceDocuments/UCM080228.pdf.

58. Gruetzmann, A., S. Hansen, and J. Muller, Novel dry electrodes for ECG monitoring. Physiol Meas, 2007. 28(11): p. 1375-90.

59. Alonso, F., M. Latorre, and K. Wårdell, Comparison of Three Deep Brain Stimulation Lead Designs under Voltage and Current Modes, in World Congress on Medical Physics and Biomedical Engineering, June 7-12, 2015, Toronto, Canada, D.A. Jaffray, Editor. 2015, Springer International Publishing. p. 1196-1199.

60. McIntyre, C.C., et al., Cellular effects of deep brain stimulation: model-based analysis of activation and inhibition. $\mathrm{J}$ Neurophysiol, 2004. 91(4): p. 1457-69.

61. Lee, J.M., et al. Evaluation of a Capacitively-Coupled, NonContact (through Clothing) Electrode or ECG Monitoring and Life Signs Detection for the Objective Force Warfighter 2004. 
62. Rattfalt, L., et al., Electrical characteristics of conductive yarns and textile electrodes for medical applications. Med Biol Eng Comput, 2007. 45(12): p. 1251-7.

63. ON semiconductor (Fairchild Semi). AN-140 CMOS Schmitt Trigger-A Uniquely Versatile Design Component. 1975 [cited 2017 March 29]; Available from: https://www.fairchildsemi.com/application-notes/AN/AN140.pdf.

64. Texas Instruments. CD4093BM CD4093BC Quad 2-Input NAND Schmitt Trigger. 1993 [cited 2017 March 29]; Literature Number: SNOS369A]. Available from: http://www.ti.com/lit/ds/symlink/cd4093bc.pdf.

65. Daniels, J. ENGN123: Bio-Instrumentation Design, Lecture: electrodes 08. 2014 [cited 2017 April 25]; Available from: http://www.brown.edu/Departments/Engineering/Courses/En123 /Lectures/electrode08.htm.

66. Frize, M., personal communication. 2006.

67. Schmidt, C., T. Flisgen, and U. van Rienen, Efficient Computation of the Neural Activation During Deep Brain Stimulation for Dispersive Electrical Properties of Brain Tissue. Ieee Transactions on Magnetics, 2016. 52(3).

68. Sotiropoulos, S.N. and P.N. Steinmetz, Assessing the direct effects of deep brain stimulation using embedded axon models. Journal of Neural Engineering, 2007. 4(2): p. 107-119.

69. Chen, Y.C., B.S. Lin, and J.S. Pan, Novel Noncontact Dry Electrode With Adaptive Mechanical Design for Measuring EEG in a Hairy Site. IEEE Transactions on Instrumentation and Measurement, 2015. 64(12): p. 3361-3368.

70. Atmel Corp. atmel-8067-8-and-16-bit-avr-microcontrollersatxmega64al-atxmega128a1_datasheet.pdf. 2013 [cited 2017 04-30]; ATXmega datasheet]. Available from: http://www.atmel.com/images/atmel-8067-8-and-16-bit-avrmicrocontrollers-atxmega64a1-atxmega128a1_datasheet.pdf.

71. Neuman, M.R., 47 Biopotential Electrodes, in Medical Devices and Systems, J.D. Bronzino, Editor. 2006, CRC Press, Taylor \& Francis Group: Boca Raton, FL, USA. p. 47.1 - 47.13.

72. Aregueta-Robles, U.A., et al., ORGANIC ELECTRODE COATINGS FOR NEXT-GENERATION NEURAL INTERFACES. Frontiers in Neuroengineering, 2014. 7. 
73. Bolin, M.H., et al., Nano-fiber scaffold electrodes based on PEDOT for cell stimulation. Sensors and Actuators B: Chemical, 2009. 142(2): p. 451-456.

74. Texas Instruments, $4 N 25,4 N 26,4 N 27,4 N 28$ OPTOCOUPLERS. 1983, Texas Instruments: Dallas, Texas, USA. p. 3.

75. Alonso, F., et al., Investigation into Deep Brain Stimulation Lead Designs: A Patient-Specific Simulation Study. Brain Sci, 2016. 6(3). 



\section{Papers}

The articles associated with this thesis have been removed for copyright reasons. For more details about these see:

http://urn.kb.se/resolve?urn=urn:nbn:se:liu:diva-138587 